Review

\title{
Application of the TTC concept to unknown substances found in analysis of foods
}

\author{
Sander Koster ${ }^{\mathrm{a}}$, Alan R. Boobis ${ }^{\mathrm{b}}$, Richard Cubberley ${ }^{\mathrm{c}}$, Heli M. Hollnagel ${ }^{\mathrm{d}}$, Elke Richling ${ }^{\mathrm{e}}$, \\ Tanja Wildemann ${ }^{\mathrm{f}, *}$, Gunna Würtzen ${ }^{\mathrm{g}}$, Corrado L. Galli ${ }^{\mathrm{h}}$ \\ ${ }^{a}$ TNO, Utrechtseweg 48, P.O. Box 360, NL 3700, AJ Zeist, The Netherlands \\ ${ }^{\mathrm{b}}$ Imperial College, Faculty of Medicine, Hammersmith Campus, Ducane Road, W120NN, London, UK \\ ' Unilever Safety and Environmental Assurance Centre, Colworth Science Park, Sharnbrook, Bedfordshire MK44 1LQ London, UK \\ ${ }^{\mathrm{d}}$ Dow Europe GmbH, Toxicology \& Environmental Research \& Consulting, Bachtobelstrasse 3, CH 8810, Horgen, Switzerland \\ e University of Kaiserslautern, Food Chemistry and Toxicology, Erwin-Schroedinger-Str. 52, DE 67663, Kaiserslautern, Germany \\ ${ }^{\mathrm{f}}$ ILSI Europe, Avenue E. Mounier 83, Box 6, 1200 Brussels, Belgium \\ ${ }^{\mathrm{g}}$ Coca-Cola Services, Chaussee de Mons 1424, BE-1070 Brussels, Belgium \\ ${ }^{\mathrm{h}}$ University of Milan, Department of Pharmacological Sciences, Via Balzaretti, 9, IT 20133, Milano, Italy
}

\section{A R T I C L E I N F O}

\section{Article history:}

Received 7 January 2011

Accepted 25 March 2011

Available online 30 March 2011

\section{Keywords:}

TTC

Threshold of toxicological concern

Foods

Analytical methods

Analysis

\begin{abstract}
A B S T R A C T
Unknown substances, not previously observed, are frequently detected in foods by quality control laboratories. In many cases, the assessment of these 'new' substances requires additional chemical analysis for their identification prior to assessing risk. This identification procedure can be time-consuming, expensive and in some instances difficult. Furthermore, in many cases, no toxicological information will be available for the substance. Therefore, there is a need to develop pragmatic tools for the assessment of the potential toxicity of substances with unknown identity to avoid delays in their risk assessment.

Hence, the 'ILSI Europe expert group on the application of the threshold of toxicological concern (TTC) to unexpected peaks found in food' was established to explore whether the TTC concept may enable a more pragmatic risk assessment of unknown substances that were not previously detected in food. A step-wise approach is introduced that uses expert judgement on the source of the food, information on the analytical techniques, the dietary consumption of food sources containing the unknown substance and quantitative information of the unknown substance to assess the safety to the consumer using the TTC. By following this step-wise approach, it may be possible to apply a TTC threshold of $90 \mu \mathrm{g} / \mathrm{day}$ for an unknown substance in food.
\end{abstract}

(c) 2011 Elsevier Ltd. All rights reserved.

\section{Contents}

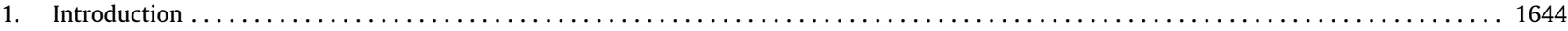

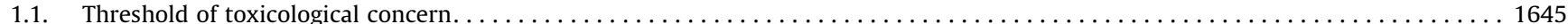

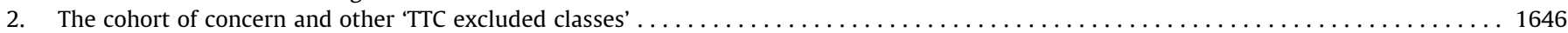

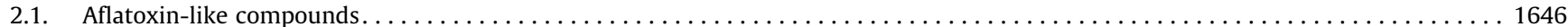

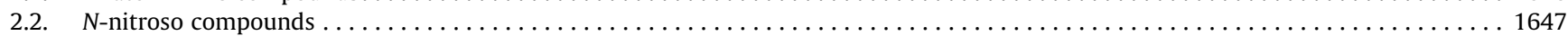

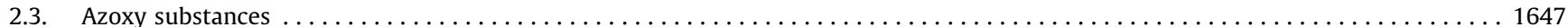

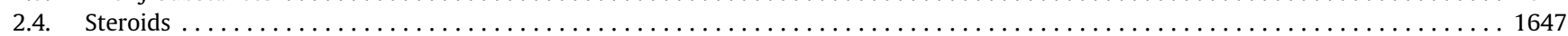

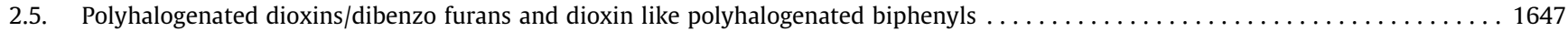

Abbreviations: AAS, atomic absorption spectrometry; ADI, acceptable daily intake; COC, cohort of concern; Corona CAD, corona charged aerosol detector; CPDB,

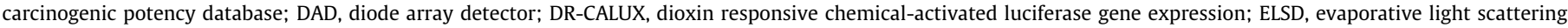

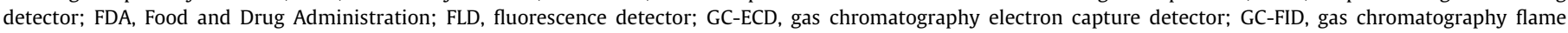

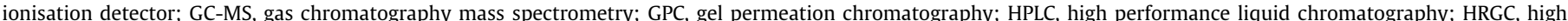

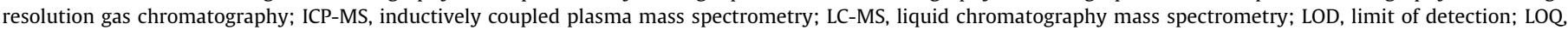

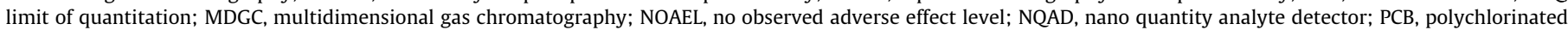

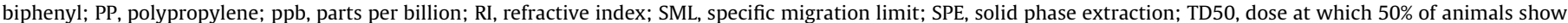
tumour; TDI, total daily intake; TLC, thin layer chromatography; ToR, threshold of regulation; TTC, threshold of toxicological concern; UV-Vis, ultraviolet-visible.

* Corresponding author. Tel.: +32 277100 14; fax: +32 27620044

E-mail address: publications@ilsieurope.be (T. Wildemann). 
2.6. Proteins . .

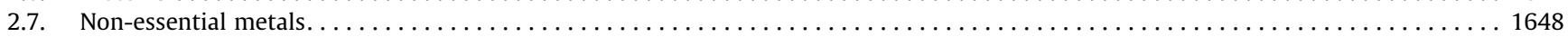

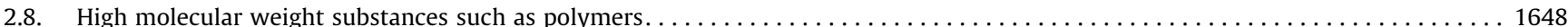

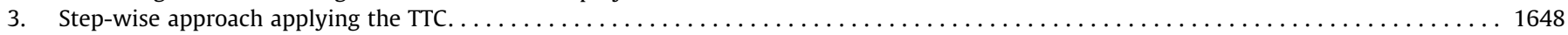

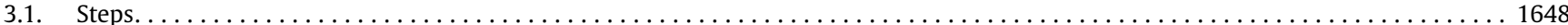

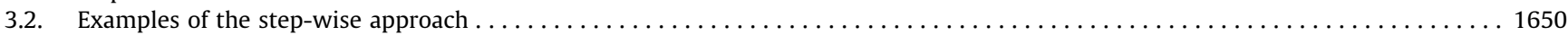

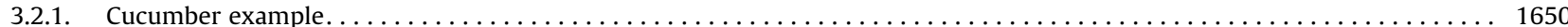

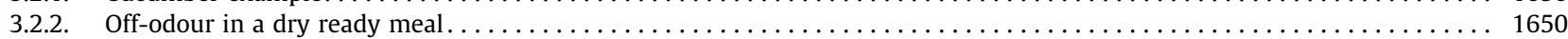

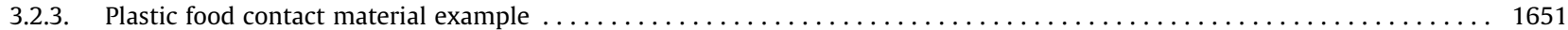

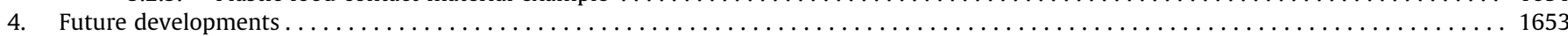

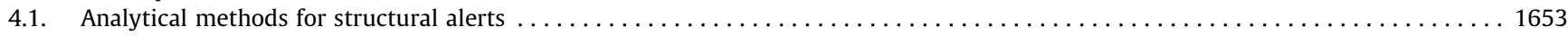

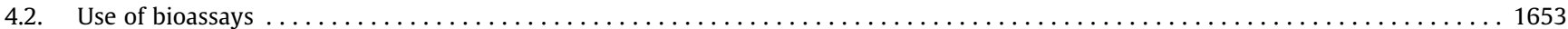

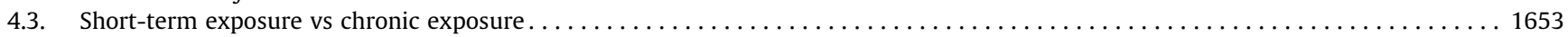

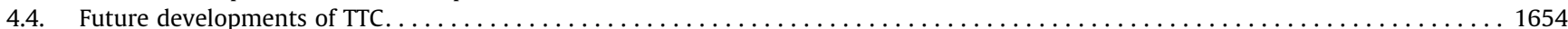

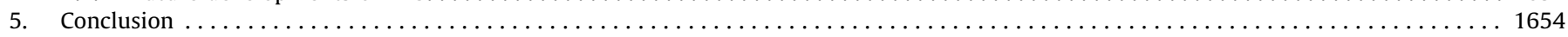

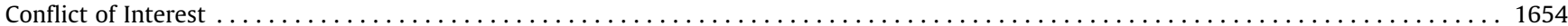

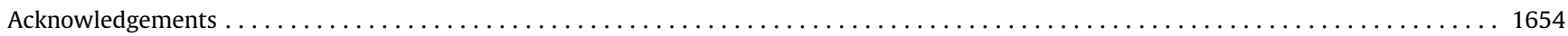

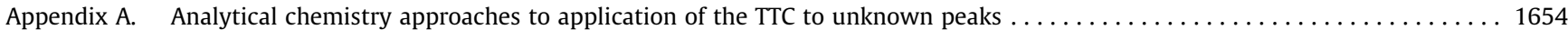

A.1. STEP 2: Exclusion by chromatographic technique, sample preparation and/or detection method used or partial identification by analytical

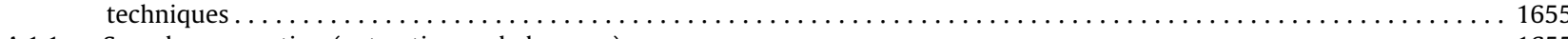

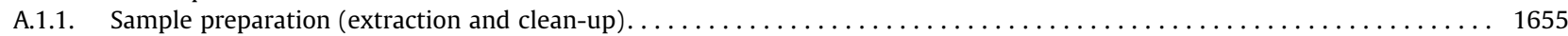

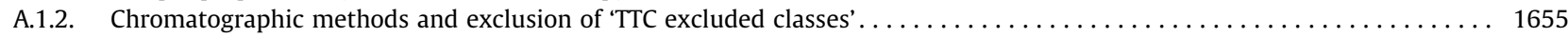

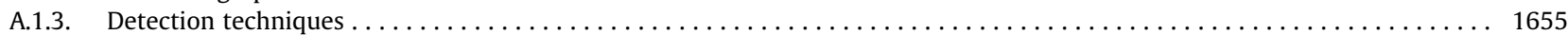

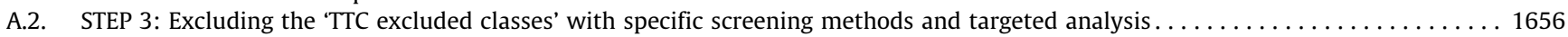

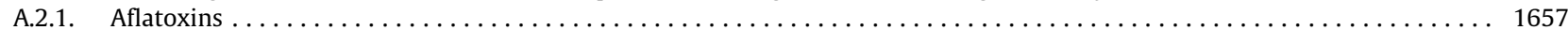

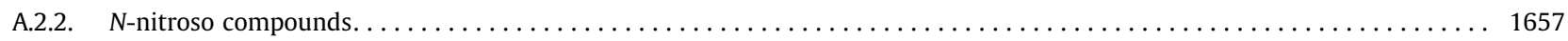

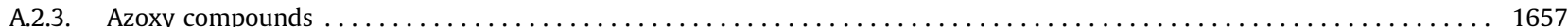

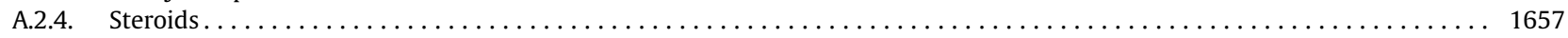

A.2.5. Polyhalogenated dioxins/dibenzo furans and dioxin like polyhalogenated biphenyls $\ldots \ldots \ldots \ldots \ldots \ldots \ldots \ldots \ldots \ldots$

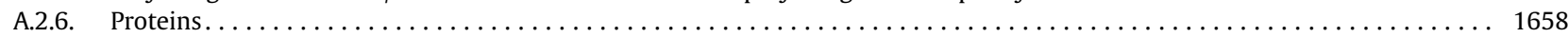

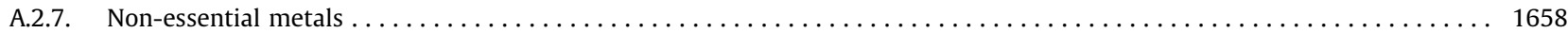

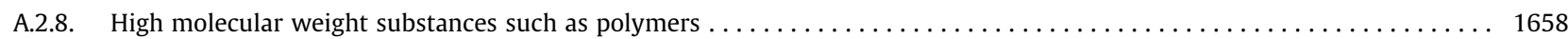

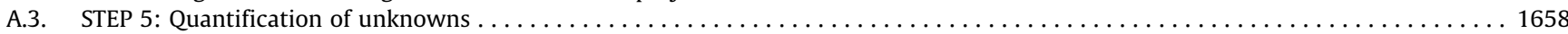

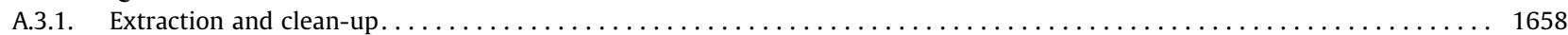

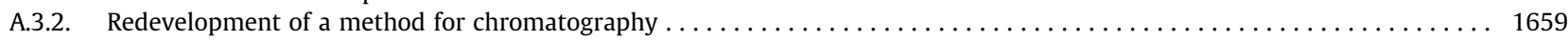

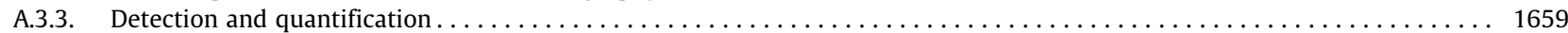

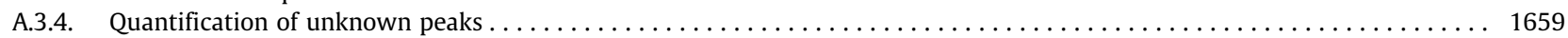

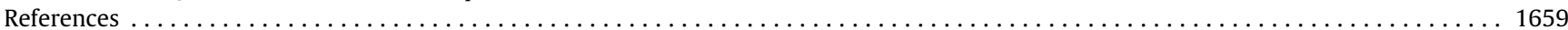

\section{Introduction}

Foods and other consumer products may contain trace amounts of certain substances, arising from various sources (e.g. agricultural practice, food formulation, food processing, food packaging). Many of these substances have known identity and origin but trace substances of unknown identity (such as impurities, hydrolysis products and reaction by-products) are regularly detected when using advanced analytical methods with increasingly lower detection limits. It is anticipated that an increasing number of such unidentified substances will be detected in the future, as analytical methods improve further. It is likely that in the majority of cases, due to their very low levels, these substances will not be of any health concern. However, at present no guidance exists on what should be done when an unknown peak is detected. Full identification of all such substances would require considerable time and effort, which would delay an initial safety assessment. Even after identification, for many, if not most, substances such as reaction byproducts, toxicological data will not be available.

The following scenarios demonstrate examples of situations where safety assessments may be required and illustrate the scope of the present paper:

(1) During routine monitoring and analysis of a food in a quality control laboratory, an unknown peak is detected that had not been seen previously in the analysis of that food. The present sample is considered to be the 'same' as previously - i.e. no known changes were made in sourcing or manufacturing conditions. Does this unknown peak pose a health concern?

(2) In the evaluation of a new processing technology (e.g. a new heat-process) a series of unknown peaks is detected at trace levels, which were not present in the food processed in a traditional manner. Are the unknown peaks a health concern?

(3) A manufacturer intends to use a new food contact material (e.g. wrapping film) containing a new additive. An unknown peak (not the additive) occurs at low level in the food. Does this unknown peak pose a health concern?

(4) A manufacturer of an approved food additive has changed the production process slightly. A comparison of the existing additive and the new product shows some minor differences that are not described in the specifications. This includes additional unknown peaks. How does the manufacturer decide if the additive has 'changed substantially' which should trigger a new safety evaluation?

ILSI Europe therefore convened an expert group to explore the possible application of the threshold of toxicological concern (TTC) concept to expedite safety assessment in such situations. The current tiered TTC concept requires knowledge of the structure of a substance, but the need for structural identification of an unknown peak would be a major roadblock in the application of the 
TTC concept, and thus the safety assessment, of such a peak. For example, scenario 1 describes the appearance of a chromatographic signal that had not been previously detected. Attempts could be made to obtain structural information using LC-MS, but full structural identification can be very time consuming and in some cases is not achievable, especially at trace levels. This paper discusses how it may still be possible in a step-wise approach to apply the TTC approach to substances detected at low concentrations, but which are not identified. It may be that identification would be laborious and would be unwarranted because conservative estimates of exposure resulting from the unknown peak are so low that its identification is of low priority once certain substances of concern have been excluded. Identification would need to be undertaken only after an initial assessment indicated that estimated exposure might exceed the relevant TTC value. Fig. 1 depicts the general principles of the approach.

Substance groups excluded from the TTC concept (see Kroes et al., 2004) are: aflatoxin-like compounds, $N$-nitroso-compounds, azoxy-compounds, steroids, proteins, polyhalogenated dibenzop-dioxins, -dibenzofurans and dioxin like PCB's, (non)-essential metals and high molecular weight substances such as polymers.

\subsection{Threshold of toxicological concern}

The threshold of toxicological concern (TTC) approach is a risk assessment tool that is based on the principle of establishing a generic human exposure threshold value for substances, below which there is a very low probability of adverse effects on human health. According to this approach, a safe level of exposure applicable to many substances can be identified, based on chemical structure and the known toxicity of other substances, which share broadly similar structural characteristics.

The first use of such an approach was the threshold of regulation (ToR) in the USA which was derived by the US FDA from analysis of 709 rodent carcinogens in the Carcinogenic Potency Database CPDB (Gold et al., 1984). The conclusion was that the risk associated with dietary concentrations below $0.5 \mathrm{ppb}$ (equivalent to $1.5 \mu \mathrm{g} /$ person/day) of substances without structural alerts for carcinogenicity/genotoxicity (DNA reactivity) is so negligible that it presents no public health concern (Rulis, 1986).

Munro and co-workers (1996) evaluated the use of TTC for endpoints other than carcinogenicity. They grouped substances from a database into three structural classes based on structural

\section{Discovery of novel unknown peak in food item}

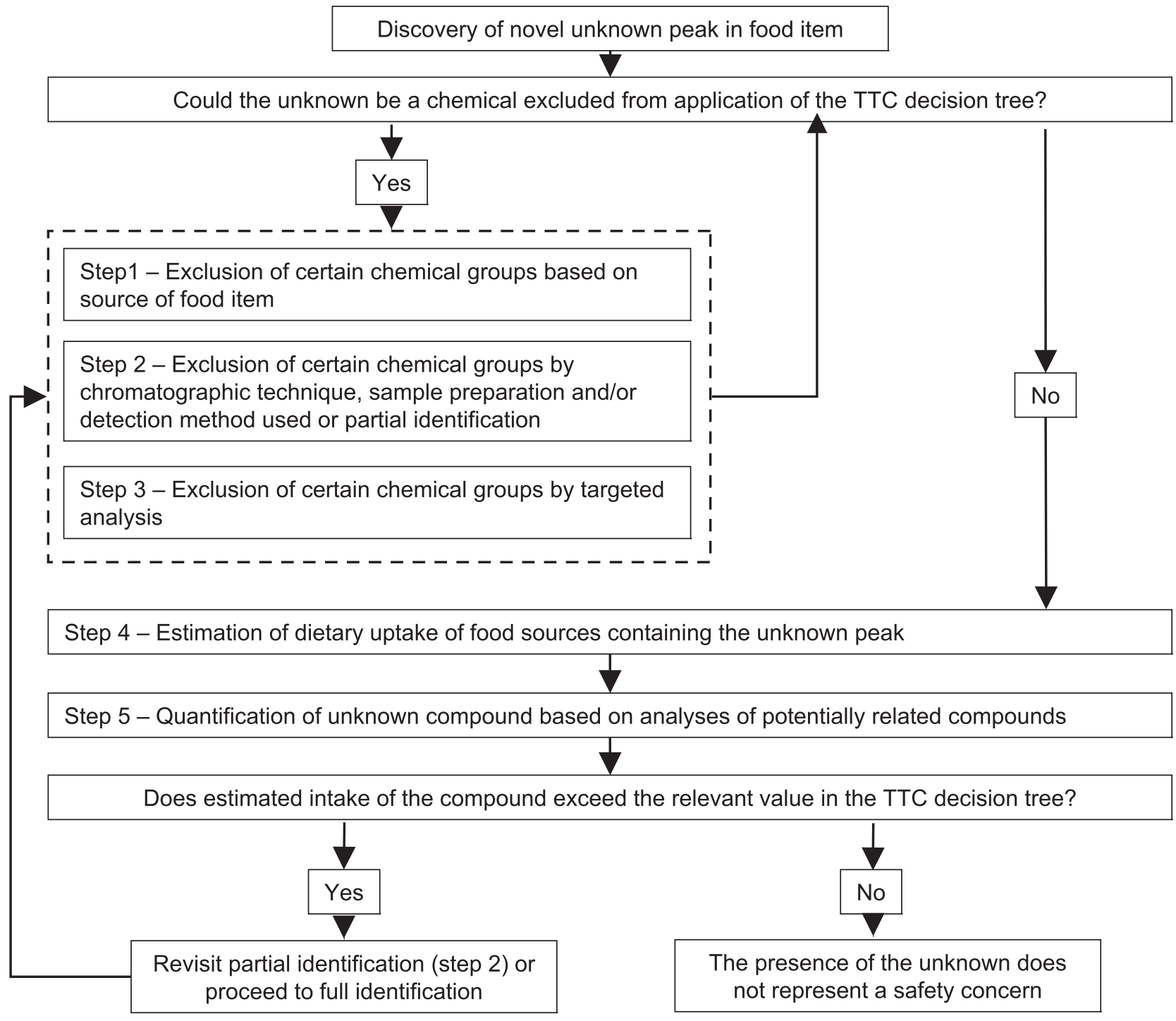

Fig. 1. Overview of the approach to the application of the TTC concept to unknown peaks. 
characteristics using the decision tree developed in 1978 by Cramer et al. Based on non-cancer endpoint effect levels of the substances, TTC values of 1800,540 and $90 \mu \mathrm{g} /$ person/day were proposed for Cramer class I, II and III, respectively.

The use of the TTC concept for substances present in the diet was discussed at two workshops (1999 and 2003) organised by the International Life Sciences Institute (ILSI), European Branch. The deliberations of these workshops and the ILSI Europe Expert Group have been published by Kroes et al. $(2000,2004)$ and Barlow (2005).

In the approach developed, certain structural groups of substances are first excluded from further consideration for application of a TTC value. These included high-potency genotoxic substances in the structural groups: aflatoxin-like compounds, $\mathrm{N}$ nitroso-compounds and azoxy-compounds. Other substances excluded were metals, proteins, steroids, dioxins, polyhalogenated furans and polymers. Following this initial exclusion step, substances containing a structural alert for possible genotoxicity are assessed using a threshold of $0.15 \mu \mathrm{g} /$ person/day $(0.0025 \mu \mathrm{g} / \mathrm{kg}$ bw/day), below which the lifetime risk of developing cancer is considered to be negligible. When the substance does not contain a structural alert that raises concern for potential genotoxicity, a TTC of $1.5 \mu \mathrm{g} /$ person/day $(0.025 \mu \mathrm{g} / \mathrm{kg}$-bw/day $)$ may be applied.

In work undertaken for EFSA (2009) on the applicability of the TTC concept in evaluating the toxicological potential of metabolites and degradation products of plant protection products, is has been suggested that a TTC of $18 \mu \mathrm{g} /$ person/day ( $0.3 \mu \mathrm{g} / \mathrm{kg}$-bw/day) (proposed by Kroes et al. (2004)) should be applied to compounds with a structural alert for neurotoxicity, excluding pyrethroids and neonicotinoids. In practice, these will be mainly organophosphates (OP) and $N$-methyl carbamates. The EFSA scientific panel on plant protection products and their residues (PPR Panel) will publish an opinion on this in due course. Recently, a revised threshold $(180 \mu \mathrm{g} /$ person/day) has been proposed by Munro et al. (2008) for Cramer class III compounds, following reanalysis of the remaining compounds in this Class after OP compounds were excluded (Munro et al. (2008)). It has been suggested that the threshold for Cramer class III may increase even further when specific other classes of substances are excluded. Without giving details for the analysis, Munro et al. (2008) increased the threshold value for Cramer class III from $90 \mu \mathrm{g} /$ person/day to $600 \mu \mathrm{g} /$ person/day when both OP's and organohalogens were excluded. Since $600 \mu \mathrm{g} /$ person/day exceeds the Cramer class II TTC ( $540 \mu \mathrm{g} /$ person/day), a TTC of $540 \mu \mathrm{g} /$ person/day was proposed for all Cramer class II and class III compounds, when OP's and organohalogens are excluded (Rennen et al. (2011)).

For any substance taken through the decision tree process, one of two recommendations will be reached: either, the substance would be expected not to be a safety concern based on the conservative TTC exposure threshold, or, its risk assessment requires refinement in terms of an exposure threshold derived from compound-specific toxicity data and/or in terms of a refined exposure assessment.

The ILSI Europe Expert Group recommended that the TTC principle can be used for substances that are present in food in low concentrations, of known structure but lacking toxicity data, for which reliable estimates of exposure can be obtained (Kroes et al., 2004). For risk assessment, the estimate of exposure is critical, since this determines whether or not the TTC is exceeded.

The situation discussed in this document is different from the applications of the TTC approach considered to date, in that it relates to substances of unknown structure, which are detected during analysis of a food or ingredient. It has been suggested in an other recent publication that TTC can be used for substances of unknown structure (Rennen et al., 2011). By looking at the origins and background of the sample and of the limitations/possibilities of the analytical methods under which the peak was found, it might be possible to reach conclusions on certain physico-chemical characteristics and thus exclude membership of some substance classes. Also, a semi-quantitative estimate can be derived of the maximum amount of the peak-substance present in the food from where the sample was taken. The degree to which there might be any health concerns associated with intake of this substance should be judged in relation to the threshold value associated with the TTC concept, as discussed below.

In general, the strategy proposed here should not be considered as a replacement for higher tier risk assessment and risk management action. Rather, it provides a pragmatic means of assessing the likelihood and magnitude of any potential concern arising from an unknown peak found in a foodstuff in situations where quick decisions are required and/or where identification would prove to be difficult and lengthy due to substance properties or low levels. Hence, if exposure to the unknown peak is below the relevant TTC, this should provide sufficient reassurance as to the potential risk to human health to enable, for example, production and distribution to continue whilst further work is undertaken. Such work could include efforts to identify the origin of the peak and steps to ensure that it no longer occurs. Alternatively, work could be undertaken to identify and, if necessary, characterise the peak. If exposure to the unknown peak exceeds the respective TTC value, depending on the magnitude of such exceedance, then either the risk assessment needs to be refined e.g. by establishing an exposure threshold based on compound specific toxicity data, by a refinement of the exposure estimates, or appropriate risk management steps would need to be considered, such as cessation of production or product recall.

\section{The cohort of concern and other 'TTC excluded classes'}

A number of substance classes are not covered by the current TTC values, see Table 1 . There are two main reasons for this: (1) some members of a class of substances are so potent that their inclusion in the database would skew the TTC to such an extent that use of the TTC would be of no practical value; (2) no or very few substances in a class were included in the database upon which the TTC values were derived. The former have been termed the "cohort of concern" (COC). This comprises three structural groups of high potency genotoxic carcinogens: aflatoxin-like compounds, $N$-nitroso-compounds and azoxy-compounds (Kroes et al., 2004). High potency non-genotoxic carcinogens, such as steroids and the dioxin-like compounds are also currently excluded. In the case of these and other non-genotoxic structural classes that are currently excluded (the 'TTC excluded classes'), it should be possible to address the situation by expanding the database with information on relevant substances, at least for some of the categories. As it is not possible to apply a TTC value to the 'TTC excluded classes', it is necessary to determine whether an unknown substance might be a member of such a class. Hence, the occurrence, relevance, and chemical structures of each of the groups of substances not covered by the TTC are discussed here. The general physical/chemical properties that could serve as a basis to differentiate between these substances and the unknown peak are considered later in the text and in the Appendix A.

\subsection{Aflatoxin-like compounds}

Aflatoxin-like compounds are widespread in nature and are produced by the Aspergillus species of fungi. Aflatoxin-like compounds belong to the family of mycotoxins. A variety of different classes can be identified and in general these mycotoxins will be found in food samples originating from plant sources (or in animal 
Table 1

The 'TTC excluded classes' not covered by TTC values, as described by Kroes et al. (2004).

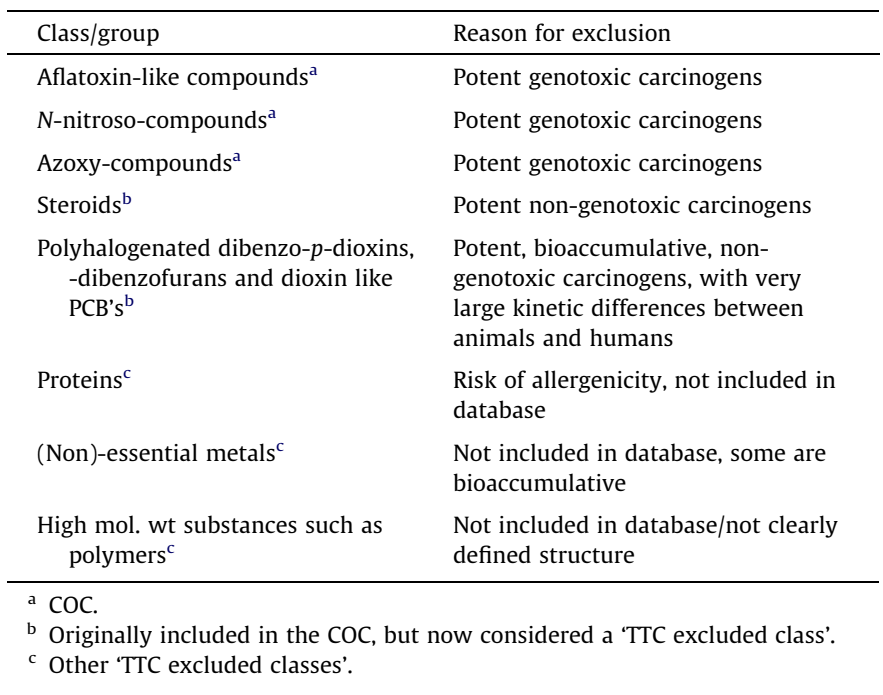

products via carry-over by feeding of contaminated plant materials). Aflatoxin-like compounds have been reported in grains (corn), nuts (pistachios, groundnut), dried fruits (figs), spices such as nutmeg, or pepper (capsicum) products (chillies). Aflatoxin-like compounds are stable when they are cooked or exposed to acidic conditions.

\subsection{N-nitroso compounds}

The term $\mathrm{N}$-nitroso compounds refers to a class of compounds comprising $\mathrm{N}$-nitrosamines and $\mathrm{N}$-nitrosamides. The substances occur as a result of reaction between nitrites and amines or amides. $\mathrm{N}$-nitrosamines are formed mostly as contaminants in heating/ combustion processes (for example tobacco smoke) or under acidic conditions such as in the stomach. Generally $N$-nitrosamides are unstable, both thermally and in non-acidic conditions. In tests, $85 \%$ of $209 \mathrm{~N}$-nitrosamines and $92 \%$ of $86 \mathrm{~N}$-nitrosamides were shown to induce cancer (Preussmann and Stewart, 1984).

$\mathrm{N}$-nitrosamines are typically associated with foods containing high levels of nitrite, such as cured or smoked foods (Walker, 1990; Scanlan and Issenberg, 1975). There are also microbiologically catalysed pathways for the formation of nitrosamines in foods (Scanlan and Issenberg, 1975).

\subsection{Azoxy substances}

Azoxy compounds are a group of chemical substances sharing a common functional group with the general structure $\mathrm{RN}=\mathrm{N}^{+}\left(\mathrm{O}^{-}\right) \mathrm{R}^{\prime}$. Azoxy compounds are $\mathrm{N}$-oxides of azo compounds (MacKenzie, 1975). Some of them are highly potent genotoxic carcinogens, which has lead to their inclusion in the COC. Their physical and chemical properties are determined by the substituents $R$ and $\mathrm{R}^{\prime}$.

Azoxy compounds find their origin mainly in dedicated complex chemical synthesis (Boyd, 1997), and it is very unlikely that azoxy substances are formed during food production/processing. The best known example of a natural azoxy substance is cycasin, a glucoside conjugate of (methyl-ONN-azoxy)methanol (MAM), which is found in the nuts, roots and leaves of Cycas circinalis $\mathrm{L}$. and Cycas revoluta. Glycosidic cleavage by bacterial $\beta$-glucosidase in the gastrointestinal lumen leads to the formation of the aglycone which is carcinogenic and has hepatotoxic, neurotoxic and teratogenic properties (Morgan and Hoffmann, 1983; Moretti et al., 1983; Laqueur and Spatz, 1968; Spatz, 1969). Other naturally occurring azoxy compounds are antifungal and carcinogenic, particularly when they contain an azoxymethane group, but their occurrence is limited to single plant species (Hasegawa et al., 1995; Parry and Müller, 1984). In general, azoxy compounds are water insoluble and yellow. The naturally occurring azoxy glycosides, cycasin and macrozamin are unstable above $140^{\circ} \mathrm{C}$.

\subsection{Steroids}

Steroids are found in plants, animals, and fungi. To date, 15,000 natural or synthetic steroids (including glycosides) have been identified (Hill et al., 1991).

Steroids were included in the original COC based on their cancer potency estimated from linear extrapolation of the TD50 to 1 in $10^{6}$ risk. However as these compounds are carcinogenic by a receptor-binding (non-genotoxic) mode of action, this method of calculating potency is not appropriate. As a consequence, Kroes et al. (2004) excluded steroids from the COC. Nevertheless, it should be recognised that there is some controversy as to the potency of steroids in a number of experimental systems, with some claims of very high potency, so that the TTC concept is currently not applied to them. Naturally occurring steroids are lipophilic.

\subsection{Polyhalogenated dioxins/dibenzo furans and dioxin like polyhalogenated biphenyls}

Polyhalogenated dibenzo- $p$-dioxins, polyhalogenated dibenzofurans and polyhalogenated biphenyls are general terms to describe three classes of compound, each consisting of several hundred potential chemical structures, known as congeners, based around a structure consisting of two linked benzene rings.

Toxic potency of these compounds is determined by the strength of binding to the aryl hydrocarbon (Ah) receptor (Poland et al., 1985). The most toxic polyhalogenated dibenzo-p-dioxins and polyhalogenated dibenzofurans congeners are those with at least 4 halogens, one attached at each of the 2, 3, 7 and 8 positions (i.e. para to each of the bridges between the two rings). The most toxic polyhalogenated biphenyls are those with 4 halogen atoms where a lack of steric hindrance allows both aromatic rings to exist in the same geometric plane.

Dioxin-like compounds were included in the original COC based on their cancer potency estimated from linear extrapolation to 1 in $10^{6}$ risk. However as these compounds are carcinogenic by a nongenotoxic mode of action, this method of calculating potency is not appropriate. As a consequence, Kroes et al. (2004) excluded the class from the COC for high potency genotoxic carcinogens. However, this group was excluded from the application of the TTC concept, mainly due to species differences in biopersistence and the existence of class-specific hazard and risk assessment schemes. Dioxin-like compounds are very hydrophobic ( $\log K_{\text {ow }}$ higher than 5).

\subsection{Proteins}

Proteins are chains of amino acids connected by peptide bonds (amide bonds). Proteins are excluded from the TTC as they may pose a risk of sensitisation or other forms of allergenicity. It has not been possible to identify a lower bound dose that would adequately protect the population against the risk of allergy from an allergenic protein because of considerable inter-individual variability in sensitivity. In addition, proteins were not included in the databases used to develop the TTC values, so that the current values cannot be applied to them. Their presence would therefore have to be excluded in the case of an unknown peak. Proteins vary from water-soluble to water-insoluble and are not volatile. 


\subsection{Non-essential metals}

In their database analysis, Cheeseman et al. (1999) included 7 compounds containing cadmium, lead and mercury. It was concluded that these were more potent than other non-genotoxic compounds, but that the threshold of regulation of $0.5 \mathrm{ppb}$ (equivalent to $1.5 \mu \mathrm{g} /$ person per day) was adequate. According to Kroes et al. (2004), metals in elemental, ionic and organic forms are not currently covered by the TTC. There are several reasons for this. Metals were not included in the database from which the TTC values were derived (Munro and co-workers, 1996). Some metals are bioaccumulative, with large species differences in their half-lives. For a number of the metals of most concern there are extensive toxicity data, which should be used in a risk assessment rather than a default TTC value. The metals of particular concern include non-essential heavy metals such as mercury, lead, cadmium, arsenic and thallium. Organic salts in which the counter-ion is an essential metal (e.g. $\mathrm{Na}^{+}, \mathrm{Ca}^{2+}, \mathrm{K}^{+}$) would be covered by the current TTC scheme.

\subsection{High molecular weight substances such as polymers}

Polymers exist in nature (e.g. cellulose, starch) and are extensively synthesised by humans (e.g. plastics). They are a diverse collection of substances with differing properties. The challenge arising with polymeric compounds is that they are normally present as mixtures of substances with a range of molecular weights. Cramer et al. (1978) excluded the application of their toxicity class scheme to polymers with the rationale that they are not structurally defined in terms of chain length, molecular weight and crosslinking. When considering cosmetic ingredients, Kroes et al., (2007) proposed that the TTC approach may be applied to oligomers and monomers present in polymeric compounds. The other aspect which needs to be considered is that the bioavailability of high molecular weight substances is very limited. Consequently, in many safety assessment schemes, only the polymer fraction below a molecular weight of $1000 \mathrm{Da}$ is taken into consideration (see e.g. EFSA, 2008a). It can be concluded that the current TTC concept can be applied only to those polymeric substances with molecular weight $<1000$ Da with sufficiently well defined structure.

\section{Step-wise approach applying the TTC}

The TTC concept as laid out by Kroes et al. (2004) assumes knowledge of the structure and exposure to the substance to be assessed. The present paper proposes a step-wise approach (see Fig. 1 and Table 2) that may allow a basic assessment of substances, the structure of which has not been identified at all, or only to a limited extent, on a case-by-case basis. At each step of the assessment, those involved will need to decide which strategy is more efficient from the perspective of time, financial and other resources, and probability of success: that is, to follow the approach proposed here or to seek complete identification of the peak to be assessed, or to run both approaches in parallel.

As indicated in previous sections, the TTC threshold of $0.15 \mu \mathrm{g} /$ day may be applied to those substances that are potentially genotoxic carcinogens, but which do not belong to the COC or other TTC excluded classes. If it is also possible to conclude that the peak in question does not have any structural alerts for genotoxicity, then a threshold of $18 \mu \mathrm{g} /$ day would apply, or $90 \mu \mathrm{g} /$ day if it can be demonstrated that the compound is not an organophosphate or $N$-methyl carbamate.

Application of the Cramer class III threshold (i.e. $90 \mu \mathrm{g} /$ day) at this step is appropriate for two reasons: firstly the absence of structural alerts for genotoxicity excludes the likelihood that a
Table 2

Overview of the proposed steps in the assessment of unknown peaks.

\begin{tabular}{|c|c|c|}
\hline & Proposed step & Background \\
\hline Step 1 & $\begin{array}{l}\text { Exclusion dependent on } \\
\text { sample source }\end{array}$ & $\begin{array}{l}\text { For some samples, it will be possible } \\
\text { to exclude the presence of some or all } \\
\text { 'TTC excluded classes' on the basis of } \\
\text { their origin }\end{array}$ \\
\hline Step 2 & $\begin{array}{l}\text { Exclusion by } \\
\text { chromatographic technique, } \\
\text { sample preparation and/or } \\
\text { detection method used or } \\
\text { partial identification }\end{array}$ & $\begin{array}{l}\text { Analytical techniques are relatively } \\
\text { specific, so that a peak detected can } \\
\text { only relate to a certain range of } \\
\text { substances or chemical } \\
\text { characteristics. They may also } \\
\text { indicate the type of substance } \\
\text { without providing a full identification }\end{array}$ \\
\hline Step 3 & $\begin{array}{l}\text { Exclusion by targeted } \\
\text { analysis }\end{array}$ & $\begin{array}{l}\text { Analyses designed to detect certain } \\
\text { structural elements can be applied }\end{array}$ \\
\hline Step 4 & $\begin{array}{l}\text { Dietary consumption of } \\
\text { food sources containing the } \\
\text { unknown substance }\end{array}$ & $\begin{array}{l}\text { Due to nutritional habits, exposure } \\
\text { depends heavily on the food type }\end{array}$ \\
\hline Step 5 & $\begin{array}{l}\text { Quantification of unknown } \\
\text { compounds }\end{array}$ & $\begin{array}{l}\text { For risk assessment, the } \\
\text { concentration of the unknown peak } \\
\text { in the sample has to be estimated } \\
\text { with sufficient accuracy }\end{array}$ \\
\hline
\end{tabular}

substance is a genotoxic carcinogen, so that a TTC based on linear extrapolation is not appropriate. Secondly, the Munro et al. database from which the Cramer/Munro thresholds were derived contains non-genotoxic carcinogens so that this type of effect is covered by these thresholds.

The approach described here is not designed either to generally exclude the presence of certain substances in the whole food item/ sample or to conclude on the safety of the whole food item/sample, but rather the objective is to assess one or a few unknown peaks already detected in a sample ${ }^{1}$.

The complexity of the assessment will depend on knowledge on the origins of the sample, potential consumption of the sampled food and the conditions of analysis having led to the detection of the unknown peak.

In the following sections, the step-wise approach will be described. It is a multidisciplinary exercise, requiring as a minimum collaboration between analytical chemistry and toxicology experts. A few examples of how this step-wise approach can be used will be given at the end of this section.

\subsection{Steps}

Step 1: Exclusion dependent on sample source

Prior information about the sample can be used to judge whether specific 'TTC excluded classes' are likely to occur in a specific product. This requires a thorough knowledge of the product with all potential contaminants that may be present. In addition, knowledge of the conditions used to manufacture the final product and/or process used, packaging, transport, and storage should be part of this expert judgement. The possibility of crosscontamination introducing compounds that were not expected has to be taken into account in the assessment. It is assumed that the analytical procedure includes quality controls to check for cross-contamination (e.g. checks of other batches of the product and repetition of the analysis). Undesired changes, for example to the organoleptic properties of the product, should be included in this assessment.

\footnotetext{
1 Note that when it can be concluded that an unknown peak does not represent a substance from the TTC excluded classes, this does not necessarily mean that the food item overall does not contain any of the substances of concern.
} 
For example, a polypropylene food contact material is very unlikely to contain dioxins, proteins, steroids, azoxy compounds or aflatoxins.

Step 2: Exclusion by chromatographic technique, sample preparation and/or detection method used or partial identification

Specific 'TTC excluded classes' can be excluded using basic analytical chemistry knowledge and evaluating the analytical technique/sample work-up procedure used. This evaluation can be based on the following analytical principles, further details of which can be found in the Appendix A:

(1) The chromatographic method used. For example, it can be excluded that an unidentified peak in a GC chromatogram is a protein, based on the physical/chemical properties of proteins.

(2) The sample preparation technique used. If a peak was detected in an aqueous extract of a meat product, dioxins can be excluded based on their solubility characteristics in water.

(3) The detection method used. For example, a peak detected with a fluorescence detector will not be a steroid as these do not fluoresce.

(4) Partial structure derived from analytical data. It may occur that a new peak can be allocated to a structural group of substances but full identification is not possible. For example the GC mass spectrum indicates that the substance is an unsubstituted alkane (i.e. contains only $\mathrm{C}$ and $\mathrm{H}$ ). If this is the case, substances in the 'TTC excluded classes', and structural alerts for genotoxicity can be excluded.

\section{Step 3: Exclusion by targeted analysis}

If the unknown peak cannot be excluded as belonging to a certain class of TTC excluded substances (e.g. $\mathrm{N}$-nitrosamines) based on the sample origin or sample preparation, it should be considered whether analyses can be performed which are specific for the TTC excluded class.

Such analytical methods are described in the Appendix A. The targeted analysis method would have to be sufficiently sensitive to detect the unknown peak (when this was detected by another analytical method with possibly greater sensitivity but not as specific).

It will often not be possible to exclude all classes of concern by theoretical considerations on the sample origin and by the methods applied or by exclusion-type analytics, so that identification of the unknown peak becomes necessary.

Step 4: Exposure estimated on consumption of food containing the unknown peak

The consumed amount of foods containing the unknown substance has to be taken into account when setting priorities for further analysis. The likelihood of adverse effects is related to the magnitude, frequency and duration of exposure to a substance.

The TTC values in current use are based on the assumption of continuous, lifetime exposure. In many cases of unexpected peaks found by analysis of a food sample, these will have arisen as a consequence of some kind of contamination. Such food is not consumed throughout a lifetime, but for shorter periods, a few days or weeks (presence in specific batches) or intermittently (appearing periodically). Evaluation of the likely consumption pattern of the food in question will allow conclusions on the exposure to the unknown peak once its concentration in the food is estimated (step 5).

In situations where the period of human intake is acute, short term or intermittent, higher thresholds may be appropriate. This has been considered in a proposal for application of the TTC concept to cosmetic ingredients (Kroes et al., 2007), where exposure was adjusted downwards by a factor of 3-fold for ingredients used only once per week and 10-fold for ingredients used less fre- quently. Similarly, Felter et al. (2009) have proposed that for trace contaminants in food with structural alerts for genotoxicity, where exposure is short term (less than one year), a TTC limit of $1.5 \mu \mathrm{g} /$ day (rather than $0.15 \mu \mathrm{g} /$ day) would be appropriate. Where exposure to genotoxic impurities in pharmaceutical ingredients is for defined periods of 1 year or less, the European Medicines Agency (EMA, 2010) uses adjustments to the conventional TTC value, depending on the duration of exposure. It is not within the scope of the present work to decide on which TTC value should be used in such circumstances. EFSA is currently evaluating this, and their recommendations should be taken into account when available ${ }^{2}$.

For estimates of consumption of specific foodstuffs, international databases might be helpful. The WHO GEMS/Food project (Global Environment Monitoring System) has collected data on consumption in relation to age groups, time of exposure and geographical area. For the EU, EFSA (The European Food Safety Authority) has established the Concise European Food Consumption Database (EFSA, 2008b), which contains data on average daily consumption of foods per person sourced from the Member States. The foods are grouped in 15 broad categories with 21 subcategories to be used as a first screening tool for EFSA and scientists in the Member States. EFSA is currently developing a comprehensive database of food consumption data. Results from analysis of one food sample showing an unexpected peak, will require a judgment of how large a part this food could cover in one of the subcategories in the tables. Methods are available to take this into account when estimating exposure.

Step 4 could include calculation of how many grams of the food containing the unknown substance in question would have to be consumed to exceed the threshold. This would give a quick overview of the situation, and indicate whether the unidentified peak is likely to be a major problem or not. An alternative would be to use the TTC to define the maximum concentration of a substance that could occur in the food without exceeding the TTC value.

Step 5: Quantification of unidentified peaks and risk characterisation Once reasonably confident that the unknown peak is not in the 'TTC excluded classes', the final step of the approach is to estimate the quantity of substance that may be present. Analytical methods for the determination of trace substances are usually developed specifically according to the properties of the individual substances in question. For known substances, analytical standards for the target substance are used so that the accuracy and precision of the analytical method can be demonstrated and the instrumental response calibrated. This, however, is not possible when the identity of the contaminant is unknown and therefore care must be taken in choosing appropriate extraction, enrichment and instrumental techniques. The general process for devising a suitable analytical method for an unknown is as follows:

(1) Utilise a non-selective extraction and clean-up procedure to prepare the unknown for detection. If appropriate, this will reflect the method by which the presence of the contaminant was originally detected.

(2) Redevelop the existing method to utilise a detection system that has a universal response and is therefore appropriate for quantifying an unidentified peak. Suitable detectors are discussed in the Appendix A.

(3) Maximise recovery by changing extraction and clean-up parameters to maximise response of the unknown.

(4) Quantify against a range of standards with suitable physicochemical characteristics, added to the sample at the target concentration derived from the TTC.

\footnotetext{
${ }^{2}$ http://www.efsa.europa.eu/en/scwgs/documents/scafttc.pdf.
} 
If the original method by which the contaminant was detected was not a chromatographic method (IR spectroscopy, for example), then a non-selective approach should be taken to "find" the contaminant by GC or HPLC prior to further refinement of the method. This will most likely involve analysis by a general method as described above with analysis of a sample where no contaminant peak was detected to serve as a control.

More details on the analytical approaches to quantifying unknowns can be found in the Appendix A.

Once the estimates from steps 4 and 5 are at hand, the daily exposure can be calculated and compared against the appropriate TTC thresholds. If the presence of a genotoxic substance cannot be excluded based on the origin and processing of the sample, the estimate of intake should not exceed the threshold of $0.15 \mu \mathrm{g} /$ person/day (or higher if an adjustment factor for short term exposure is accepted). If the estimated intake is below this value, the intake is in an area of negligible risk, and it is again a case-by-case decision as to whether further action is considered necessary. If it can be excluded that the unknown peak is a genotoxic substance (or contains a structural alert for genotoxicity) and the analyses indicate that the substance does not belong to the 'TTC excluded classes', organophosphates or $\mathrm{N}$-methyl-carbamates, comparison of the estimated intake of the specific food with the TTC of $90 \mu \mathrm{g} /$ person/day (or corrected by a factor for short term exposure) will indicate whether the peak is of toxicological concern. If so, the need for chemical identification and optimisation of the analytical method would then be a likely risk management decision.

Application of the TTC approach to unknown substances as described above should provide the initial step in risk characterisation for the unknown peak and should help to quickly identify those problems that need more thorough research.

\subsection{Examples of the step-wise approach}

Three examples are described below in which the step-wise approach was applied to an unknown peak not detected previously. It is discussed how each of the steps can be used in practice. For the three examples, the step-wise approach helped in reaching a conclusion that the unknown peak posed no risk to consumer safety.

\subsubsection{Cucumber example}

During a pesticide screen of cucumber extracts by GC-MS, a peak was detected that was not normally seen in cucumber, nor did it match the retention time of any pesticide for which a standard was available. The sample had been extracted with mixed polarity solvents and purified by gel permeation chromatography to allow the analysis of a range of substances with different properties.

The presence of the unidentified peak was assessed using the step-wise approach to the TTC in order to assess consumer safety.

Step 1. Sample source

Cucumber is a watery fruit that contains negligible amounts of fat and therefore the presence of dioxin-like compounds can be ruled out. $\mathrm{N}$-nitroso compounds are formed in the presence of nitrites and are more associated with processed foods than fresh fruit and vegetables and so are also excluded. Azoxy compounds find their origin mainly in dedicated complex chemical synthesis (Boyd, 1997) and are very unlikely to be formed during food production/processing. Azoxy compounds were therefore discounted at this stage.

Step 2. Analytical method

Samples were purified by gel permeation chromatography (GPC) used for size/molecular weight separation to remove large molecules such as proteins and lipids. Analysis was then carried out by GC-MS with the unknown peak eluting at 11.66 min when the oven temperature was approximately $200{ }^{\circ} \mathrm{C}$.
Proteins and large molecular weight polymers would be filtered out by GPC and also would not be amenable to GC analysis and are therefore excluded. Steroids can be analysed by GC but typically they are only semi-volatile at best and require very high oven temperatures $\left(>275^{\circ} \mathrm{C}\right)$ so would not be expected at the retention time of this peak. Aflatoxins are not sufficiently volatile for GC analysis so it can be concluded that the unknown peak is not an aflatoxinlike substance.

Attempts at partial structural identification from the mass spectrum of the unknown peak were inconclusive with no library match and no characteristic ions to interpret. Therefore, not enough is known of the structure of the unknown peak to determine whether or not it might be a genotoxin.

Step 3. Exclusion by targeted analysis

The presence of metals (as volatile organometallics) cannot be ruled out based on the first 2 steps. The sample was sent for trace metal analysis by ICP-MS and was found to contain metals within the normal concentration range for cucumber samples.

Step 4. Dietary consumption of food sources containing the unknown peak

As the unidentified peak could be potentially genotoxic, the TTC value of $0.15 \mu \mathrm{g} /$ day would apply. Cucumber intake of $6.5 \mathrm{~g} /$ day (UK National Statistics, 2001) was used in the calculation. Therefore, the maximum concentration of the unknown peak that could be considered not to represent a risk to human health would be $23 \mu \mathrm{g} / \mathrm{kg}$ of cucumber.

Step 5. Quantification

Cucumber was spiked with a range of substances, many of which were the standards for which the method that detected the unknown had been optimised, at the action level defined above $(23 \mu \mathrm{g} / \mathrm{kg})$. The spiked cucumber was analysed by the same extraction-GPC method as previously used. By using a range of substances as standards it was considered that recovery, detector response and matrix effects were corrected automatically. The responses of the standards should be compared and the mean used as the level of concern if there is reasonable equivalence of response (RSD $<30 \%$ ), otherwise the lowest response of the standards should be used as the level of concern. The response of the unknown must be less than the level of concern for the risk to be judged acceptable.

A sample of cucumber was fortified with the following contaminants, each at $23 \mu \mathrm{g} / \mathrm{kg}$ : $\alpha-\mathrm{HCH} ; \mathrm{HCB} ; \beta-\mathrm{HCH} ; \delta-\mathrm{HCH}$; heptachlor; aldrin; heptachlor epoxide; $\alpha$-lindosulfan; $\mathrm{pp}^{\prime}$-DDE; dieldrien; endrin; $\beta$-endosulfan; $\mathrm{pp}^{\prime}$-TDE + op'-DDT; $\mathrm{pp}^{\prime}$-DDT; methoxychlor; acrylamide; benzene; 2,4,6-trichlorophenol; 2,4,6-trichloroanisole Analysis was carried out as follows:

- Homogenised, extracted using acetone, ethyl acetate/cyclohexane $(50 / 50)$.

- Crude extract filtered and cleaned-up using gel permeation chromatography.

- Final extract reduced to $1 \mathrm{~mL}$ volume.

- Unspiked cucumber also reanalysed.

Not all the responses of the standards are resolved from the matrix background. Only standards that were well resolved from other peaks, were used in quantification. The mean response (peak height) of the other reference compounds is set as the level of concern, in this case $23 \mu \mathrm{g} / \mathrm{kg}$. The peak of interest at $11.66 \mathrm{~min}$ was below this level and therefore was not considered a risk to consumer health (see Fig. 2).

\subsubsection{Off-odour in a dry ready meal}

Consumers noticed a strange smell on preparation of a dry ready meal. It was important to assess the risk to the consumer from consumption of this product. 
The distinctive odour was traced to a single ingredient (dried vegetable) and this was analysed for volatile contaminants by headspace-GC-MS. Two unknown peaks not present in normal samples were detected. The first was identified from its mass spectrum as toluene and this was quantified using toluene as an analytical standard. The second peak was reanalysed on a headspace GC system with an olfactometer. A trained specialist confirmed that the second peak caused the off-odour. Since the identity of the peak was still unclear the step-wise approach to the TTC was applied as follows:

Step 1. Sample source

The affected ingredient was a processed dried vegetable and caused a distinct off-odour. Contamination was likely to have occurred during processing.

Based on the assessment by GC-olfactometer, it is reasonable to assume that the unknown peak caused the off-odour described by consumers. Aflatoxins, steroids, proteins, non-essential metals and high molecular weight compounds are not sufficiently volatile to contribute to an off-odour. Contamination of foods with dioxins and PCBs has been extensively reported but there are no accounts of an associated off-odour. $N$-nitrosamines typically have only a faint odour. Therefore, the only TTC excluded compounds not excluded are the azoxy compounds, the odour of which is unknown. However, as discussed in the cucumber example azoxy compounds can be discounted at this stage. Therefore, it is reasonable to exclude all the TTC excluded classes at this stage.

Step 2. Exclusion by analytical method

Analysis was conducted by headspace GC-MS so only volatile substances would be detected. This would lead to the exclusion of aflatoxins, proteins, steroids, dioxin-like compounds, high molecular weight polymers and non-essential metals.

Partial identification using the mass spectrum of the unknown peak showed the presence of a chlorine isotope pattern and additional fragment ions that indicated it was likely that the unidentified peak was a trichlorinated substituted benzene compound. Trichloroanisoles and trichlorophenols were the closest matches to the mass spectrum, neither of which is genotoxic but both of which produce distinct off-odour at low concentrations. They can both be formed due to insufficient removal of chlorinated cleaning solutions used to disinfect food manufacturing facilities and so the presence of a substance of this type is plausible. However, the unknown cannot be identified clearly as neither its mass spectrum nor its GC retention time matches that of any of the analytical standards available.

Step 3. Exclusion by targeted analysis

All 'TTC excluded classes' could be excluded in step 1 since they do not give rise to odours. Additionally, some structural information was deduced in step 2 . Therefore, no targeted analysis was required to exclude the 'TTC excluded classes' of compounds.

Step 4. Dietary consumption of food sources containing the unknown peak

The risk assessment was to be based on consumption of one ready meal per day $(50 \mathrm{~g})$ containing $1 \mathrm{~g}$ of the contaminated ingredient. Since there is sufficient information on the chemical structure to be able to rule out both gentoxic substances, organophosphates and $\mathrm{N}$-methyl-carbamates, the relevant TTC threshold is $90 \mu \mathrm{g} /$ day in this case. This means the maximum concentration in the ingredient without concern would be $90 \mu \mathrm{g}$ in $1 \mathrm{~g}$ of the contaminated ingredient or $90 \mathrm{ppm}$.

\section{Step 5. Quantification}

Samples $(1 \mathrm{~g})$ of the contaminated dried vegetable were spiked with isomers of trichlorophenol and trichloroanisole as standards, compounds believed to be similar in properties to the contaminant based on the mass spectra. The response of the instrument to the standards was determined and used to estimate the concentration of unknown in the food. This was used to specify an appropriate spiking concentration to give a response similar to that of the unknown peak. Analysis was by headspace GC-MS and the unidentified contaminant was quantified based on the mean response factor of the related compounds.

In this case the unidentified peak was determined to be at a level significantly below $90 \mathrm{ppm}$ and the risk to consumer safety was deemed acceptable. However, the product was considered unpalatable and was withdrawn from sale on the basis of quality grounds.

\subsubsection{Plastic food contact material example}

A new chain transfer agent is under development to improve the properties of polypropylene (PP) food contact resin. Laboratory scale and pilot plant resins have been produced with the new material. The new type of resin is extracted with toluene and analysed by gas chromatography/FID. The new chain transfer agent is not detected in the extract, as it decomposes in the polymer
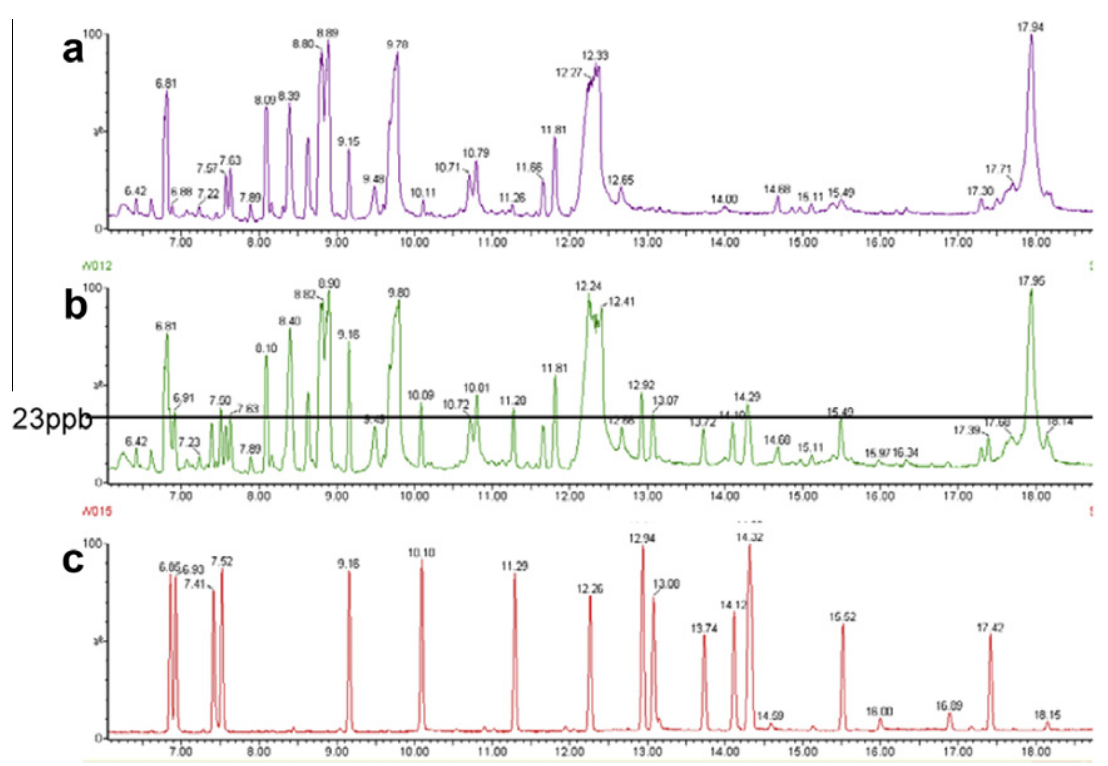

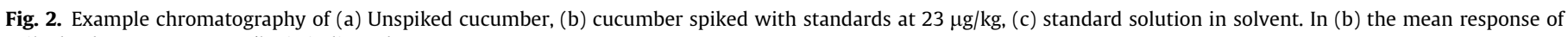
spiked substances at $23 \mu \mathrm{g} / \mathrm{kg}$ is indicated. 
production process. The analysis reveals two additional unknown peaks at low level, which were not present in the solvent extracts of the conventional food contact resin. The two unknown peaks are a doublet located at $15.85 \mathrm{~min}$ and $15.90 \mathrm{~min}$. The low height of the peaks prevents their identification from the extract.

Step 1. Sample source and Step 2 chromatographic technique used, sample preparation and/or detection method

The new chain transfer agent is an organic substance that is insoluble in aqueous, acidic media, but is soluble in food oil, 95\% ethanol and isooctane. Several potential breakdown products have been theorised, but none are commercially available compounds. Similar solubility properties as for the parent compound are expected for these breakdown products. From the structure of the chain transfer agent or potential breakdown products, one can conclude that the unknowns in the solvent extract are not polyhalogenated dioxin, -dibenzofuran, or -biphenyl compounds. Metals or metal-containing compounds are also excluded from knowledge of the process chemistry and also they would not be detected by this analytical technique. Likewise, process chemistry and the chemistry of the chain transfer agent eliminate non-essential metals, azoxy-, or $\mathrm{N}$-nitroso-compounds as possible unknowns. Aflatoxin-like compounds, polymers and proteins are excluded by the chromatographic techniques.

Step 3. Targeted analysis

Targeted analysis for the 'TTC excluded classes' is not necessary, as sample source and analytical technique allow a conclusion that the unknown peak does not belong to any of those classes.

Step 4. Dietary consumption of food sources containing the unknown peak

The risk assessment was based on standard assumptions of consumption of $200 \mathrm{~g}$ food per day (EFSA, 2008a) using the fat reduction factor of 5 (see Commission Directive, 2007/19/EC April 2, 2007) packaged in the respective material. Applying the TTC of $0.15 \mu \mathrm{g} /$ day for the two unknown peaks means the maximum concentration in the food without concern would be $0.75 \mu \mathrm{g} / \mathrm{kg}$. If one can determine that the two unknown peaks migrate to fatty food simulant below a level that would correspond to an exposure of $0.15 \mu \mathrm{g} / \mathrm{day}$, then according to the TTC concept the two unknowns would present a negligible risk.

\section{Step 5. Quantification}

The upper chromatogram in Fig. 3 is for the solvent extract in which the presence of the two unknown peaks was detected. Note that the peaks detected in the toluene solvent extract are representative of what is in the resin, but not necessarily of what will migrate into food. The solvent extracts are applied to simplify the check for potential migrants, as they contain higher concentrations of the substances than migration solutions. To estimate the level of migration into food and from there the exposure, migration simulation experiments were conducted. As the intended use of the material is in packaging of fatty food, the standard fatty food simulants $95 \%$ ethanol and isooctane were applied in the migration experiments. Film samples of the PP resin were obtained and a migration study was conducted. The $95 \%$ ethanol experiment was carried out at $40^{\circ} \mathrm{C}$ for 10 days, while the isooctane experiment was conducted at room temperature for $48 \mathrm{~h}$ [Directive 82/711/ EEC, Chapter III, Table 4]. The volume to surface ratio in the migration test was $25 \mathrm{~mL} / \mathrm{dm}^{2}$ or $150 \mathrm{~mL} / 6 \mathrm{dm}^{2}$. This means that a concentration of $0.75 \mu \mathrm{g} / \mathrm{kg}$ in the food would correspond to a concentration of $1000 / 150 \times 0.75=5 \mu \mathrm{g} / \mathrm{L}$ in the food simulant.

The applied standard (tetradecane) and the components of interest are assumed to have similar detector responses based on the application of a universal detector, the response of which is based on carbon mass. The level of $5 \mu \mathrm{g} / \mathrm{L}$ standard spiked into the migration solutions would correspond to an exposure level of $0.15 \mu \mathrm{g} /$ day under the following assumptions (Commission Directive, 2007/19/EC April 2, 2007):

- Consumption of food packaged in the respective material: $200 \mathrm{~g}$ per day (fat reduction factor of 5).

- Surface of resin in contact with the food: $6 \mathrm{dm}^{2} / \mathrm{kg}$ food.

- Volume of food simulant exposed to the resin surface: $25 \mathrm{~mL} /$ $\mathrm{dm}^{2}$ (enhanced surface to volume ratio) $(0.15 \mu \mathrm{g} /$ day $\times$ day $/$ $0.2 \mathrm{~kg}$ food $\times 1 \mathrm{~kg} / 6 \mathrm{dm}^{2} \times 1 \mathrm{dm}^{2} / 25 \mathrm{~mL} \operatorname{sim}=5 \mu \mathrm{g} / \mathrm{L}$ simulant $)$.

Fig. 3 depicts the chromatographic overlay of the solvent extract analysis (top chromatogram) and the two food simulants (middle chromatogram - isooctane, lower chromatogram - 95\% ethanol). The chromatogram shows that the unknown peaks (see dashed

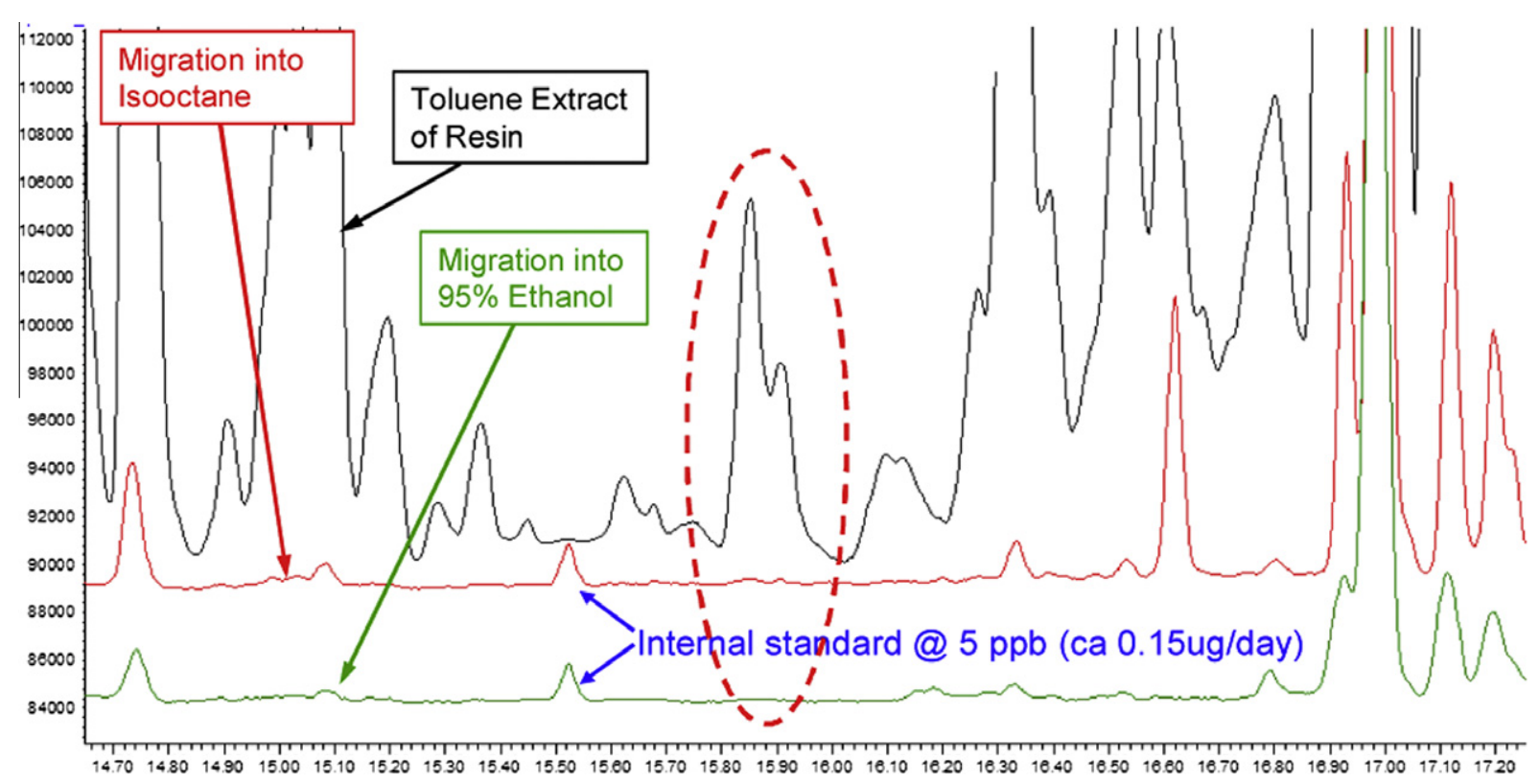

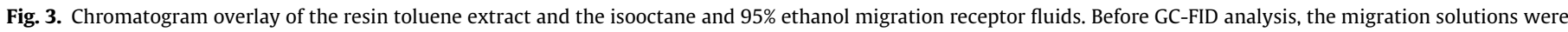
fortified with an internal standard at a concentration of $5 \mu \mathrm{g} / \mathrm{l}$. The dashed oval indicates the peaks of interest. 
oval) are only detected in the toluene extract of the polymer and not in the $95 \%$ ethanol or isooctane exposed to the plastic film in the migration studies. In contrast, the internal standard was detectable at $5 \mu \mathrm{g} / \mathrm{L}$ in both $95 \%$ ethanol and isooctane. Therefore it can be concluded that the two unknowns, while being present in the plastic, do not migrate into the fatty food simulants at a level equivalent to an exposure of $0.15 \mu \mathrm{g} / \mathrm{day}$ or above. Therefore, the two unknowns are not likely to be a safety concern.

It should be noted that the toluene extracted much more material from the PP resin than the food simulants. It should also be noted, that without knowing the identity of the chain transfer agent, the process conditions and likely breakdown products, it would not be possible to exclude the COC.

\section{Future developments}

To be able to conclude that an unidentified peak does not pose a concern for health requires first that it can be shown not to belong to a 'TTC excluded class'. Dedicated analytical techniques are available for most of these classes and hence specific research to further develop these techniques is not a high priority. Of course, developments where cost-efficiency and speed of analysis are improved are always desirable.

\subsection{Analytical methods for structural alerts}

Potential genotoxicity needs to be evaluated when assessing the safety of an unknown peak (e.g. Ashby et al., 1989). Structural alerts are functional groups such as azoxys, aromatic amines, alkyl aldehydes and propiolactones/propiosultones. If one can demonstrate that an unknown peak does not comprise a molecule containing structural alerts for genotoxicity, the chance that it has genotoxic potential is low.

An approach to exclude the presence of these structural alerts from a complex matrix is by developing analytical methods to detect structural alerts, for example by labelling the functional group of interest and selective detection by fluorescence or by studying mass spectrometric fragmentation pathways indicative for a specific functional group. Aromatic amines for example can be derivatised by pentafluorobenzoyl chloride followed by GC-MS (Coulier et al., 2008). Although this approach is promising, it is questionable whether sensitive and selective methods can be developed to exclude all structural alerts. It may therefore be more realistic to develop biological assays that allow detection of genotoxicity at a relevant concentration.

Many assays exist that will give an indication of the genotoxic potential of substances, however most of these were developed to test pure known substances at high concentrations. These tests are unsuitable for the application described in this paper i.e. unknown peaks at low concentrations in food or ingredients. Therefore, more research is needed to make these or other tests suitable for testing unknown substances at low concentrations. Some recent developments are described below. Further developments are needed to decide whether or not the unidentified peak is a possible genotoxin.

\subsection{Use of bioassays}

TTC values are based on the toxicological activity of chemicals. Certain groups of substances are excluded from application of a TTC value because of their very high biological potency. Such substances include certain groups of genotoxic carcinogens, and dioxin-like compounds (in part these are also excluded because of species differences in their biopersistence, as are non-essential metals). Each group exhibits a certain pattern of biological effects while their chemical structures may be diverse. Hence, the use of generic screens for biological properties relevant to the toxicity of these compounds would be very advantageous in the development of a strategy such as that proposed in this paper.

Over the last few years a range of biosensor systems have been developed (Rogers, 2006). An example of such a biosensor is the DR-CALUX system for dioxin-like compounds. This and related assays are sufficiently sensitive for screening complex samples, including foodstuffs, for the presence of dioxins and related compounds (Scippo et al., 2004a; Jeong et al., 2005; De Hoogenboom et al., 2006; de Waard et al., 2008).

In the case of heavy metals, both substance and class-selective biosensors have been developed. Metal-responsive elements that have been used include those from metallothionein (Varriale et al., 2007; Gutiérrez et al.,2009), from regulator proteins (Radhika et al., 2005) and from phytochelatins (Bontidean et al., 2003).

In the case of genotoxins, whilst the priority within the context of the TTC strategy proposed, is to exclude those potent genotoxins in the COC, there would be considerable value in being able to exclude all DNA reactive genotoxins, providing that the limit of detection was consistent with the TTC values that would need to be used (e.g. $0.15 \mu \mathrm{g} /$ day intake for lifetime exposure). DNAreactive genotoxins, which include those in the $\mathrm{COC}$, form covalent adducts with DNA. Depending on the nature of the adduct, a specific DNA repair response is stimulated, the components of which are encoded by genes containing response elements amenable to the development of biosensor systems. These assays have been developed primarily for use in in vitro genotoxicity screening of pure compounds, and their utility in screening complex matrices such as food has not been investigated to any appreciable extent.

The current limitations of most biosensors, including those for genotoxins and heavy metals, when applied to food are analytical sensitivity and, because they involve intact, cell-based systems, interference from other components in the matrix.

The latter may act either to mask a response, for example due to scavenging of reactive species, or to induce a response in the absence of a substance of concern. However, it should be noted that many natural ingredients of traditional foods will result in positive findings in classical genotoxicity assays and also in reporter gene assays. Whilst these may be of no concern due to the 'history of safe use', it would be difficult to rule out these food matrix related positives in highly sensitive bioassays. Hence, in practice, such assays are most likely to find application in the analysis of (partially) resolved peaks.

Whilst there is obvious potential for the application of biosensors in the strategy proposed, they are not yet sufficiently reliable and/or suitable for this purpose, although this may not always be so. It may well be possible that future developments are such that very sensitive, robust biosensors, suitable for screening foods samples, will eventually become available.

The necessary limit of sensitivity of such assays could be determined using step 4 methodology, on either a food matrix or on a fraction from an HPLC column. Hence, the amount of the food in question, or equivalent to the volume of column effluent, that would have to be consumed to exceed the threshold could be calculated, based on appropriate data for consumption of the food, as explained above.

\subsection{Short-term exposure vs chronic exposure}

The current TTC values are based on the assumption of continuous lifetime exposure. However, there will be situations where the TTC concept might be appropriate, but exposure is for less than lifetime (or may be intermittent). It has been suggested that, in such situations, it might be appropriate to adjust the lifetime TTC values, to allow for this (e.g. Humfrey, 2007; Felter et al., 2009). 
The issue of adjusting lifetime estimates of risk for shorter durations of exposure has been addressed more broadly by the ILSI Health and Environmental Sciences Institute. They have developed a framework approach to this, which will be published in the peer reviewed literature, some time in 2011 (Felter et al., in press). The framework is relevant for assessing compounds with bioassay data that can support a substance-specific risk assessment, and also those lacking data, in which case TTC is recommended as a conservative starting point for the assessment.

\subsection{Future developments of TTC}

The TTC concept has been continuously developed over the last decades. New toxicological studies and database evaluations have been performed in the years after its initial introduction and gave new toxicological insights that were implemented in new TTC thresholds and new classes of substances were introduced that required special attention within TTC. At the same time, many of the evaluations of specific classes of substances concluded that the initial thresholds are sufficiently conservative to cover their effects. The increasing amount of data becoming available on various types of substances and different endpoints and exposure routes will broaden the database, thus increasing the confidence in the thresholds, and enable a refinement of the substance groupings. Such developments can be readily incorporated into the approach described in this paper. Newly defined thresholds would be part of step 4 of this work. Also, any potential new 'TTC excluded classes' could be evaluated in a manner, similar to that for the substances described in this paper.

\section{Conclusion}

The step-wise approach detailed above provides a method for application of knowledge of both analytical chemistry and toxicology to conduct safety assessments when an unexpected, unidentified substance is detected in food. The approach described seeks to meet safety assessment needs in situations when it is analytically difficult to identify a substance, an assessment is needed urgently and/or when the number of peaks is such that it is not feasible to evaluate all of them completely with available resources. Using information on the history of the sample, the behaviour of the substance during chemical analysis and compound class-specific analytical techniques it may be possible to rule out the presence of certain classes of compounds (the 'TTC excluded classes') and therefore allow application of the TTC approach in the risk assessment. Approaches to estimate the quantity of the unknown substance that is present and therefore exposure are discussed, and TTC-based risk assessment has been illustrated with some examples.

It is important to recognise that this approach is limited to the presence of unexpected substances that have been detected already. It cannot be used as a general screen of foodstuffs for safety. The key to this approach is that the substance under assessment is detectable, i.e. is present above the limit of detection of the applied analytical method. Due to technical limitations, it cannot be assumed that all potential toxicants are detected in every analysis. Therefore this approach assesses the potential impact of a specific detected unknown and does not assure overall food safety, for which other strategies have been developed.

This approach can be widely applied, although it may be limited by a lack of knowledge of sample history or inconclusive analytical behaviour. It should always be considered whether pursuing the step-wise approach presented here is an efficient alternative to identification of the substance by a set of enrichment and analytical techniques (including for example, NMR spectroscopy of an isolated fraction of the substance).

Whereas the presence of the 'TTC excluded classes' can be assessed by a combination of expert judgement and targeted chemical analysis, determining whether the unknown substance presents a genotoxicity concern is unlikely to be possible without at least some structural information. The assays presently available for assessing genotoxicity are not sufficiently sensitive or selective to be applied to trace level substances in complex food matrices. Whilst some information may be gained from mass spectrometry there will be many cases when safety assessments need to be conducted without structural information, assuming the worst-case scenario that the substance is a genotoxic carcinogen. It is likely that if the unknown substance can be readily detected that it will be present at a concentration that leads to exposure above the TTC level of $0.15 \mu \mathrm{g} / \mathrm{day}$, and consequently the risk to consumers would have to be assessed in more detail. It is hoped that in the future, more sensitive assays for determining genotoxic potential will be developed allowing the genotoxicity of trace substances in complex matrices to be adequately assessed and higher steps of the TTC to be used more routinely in risk assessment.

Key to the application of the TTC approach to risk assessment is consumer exposure to the contaminated foodstuff. For foods consumed in relatively small amounts (e.g. herbs and spices) even readily detectable levels of an unknown peak may result in consumption of significantly less than $0.15 \mu \mathrm{g} /$ day with no need to assess genotoxicity.

The TTC approach is useful in evaluating unknown substances in food. It is acknowledged that limitations, as described above, could restrict the range of application somewhat. However, future developments in analytical chemistry and genotoxicity assays should reduce these limitations.

\section{Conflict of Interest}

The authors declare that there are no conflicts of interest.

\section{Acknowledgements}

The authors would like to thank Prof. Andrew Renwick and Dr. David Carlander for their advice in the preparation of the manuscript.

The expert group would like to thank Prof. Corrado Galli for chairing this expert group.

This work was commissioned by the Threshold of Toxicological Concern Task Force of the European branch of the International Life Sciences Institute (ILSI Europe). Industry members of this task force are Coca-Cola Europe, Danone, Dow Europe, DSM, Givaudan, L'Oréal, Nestlé, Procter \& Gamble and Unilever. This publication was coordinated by Tanja Wildemann, Scientific Project Manager at ILSI Europe. For further information about ILSI Europe, please email info@ilsieurope.be or call +32 277100 14. The opinions expressed herein and the conclusions of this publication are those of the authors and do not necessarily represent the views of ILSI Europe nor those of the supporting companies.

Alan Boobis, Corrado L. Galli, Sander Koster and Elke Richling received an honorarium from ILSI Europe for their participation in this publication and/or reimbursement of their travel and accommodation costs for attending the related meetings.

\section{Appendix A. Analytical chemistry approaches to application of the TTC to unknown peaks}

Key to the routine use of the TTC approach in assessing the risk of an unknown peak in food is the analytical chemistry behind the 
detection of the unknown. This Appendix A will look in detail into the analytical chemistry and how it relates to the step-wise approach outlined earlier in this paper. Three steps of the approach involve analytical chemistry and are relevant for the scope of this Appendix A:

Step 2. Exclusion by chromatographic technique, sample preparation and/or detection method used or partial identification by analytical techniques.

Step 3. Excluding the COC and other TTC excluded classes with specific screening methods and targeted analysis.

Step 5. Analytical approaches to the quantification of unknowns.

\section{A.1. STEP 2: Exclusion by chromatographic technique, sample preparation and/or detection method used or partial identification by analytical techniques}

The analytical method by which an unknown peak is first detected can give information on the properties of the unknown peak and clues as to its identity. It is therefore possible to exclude the presence of 'TTC excluded classes' by reviewing the analytical approaches taken initially and considering the predicted fate of the TTC excluded classes by the method used.

This evaluation can be based on three main analytical principles:

(1) Sample preparation technique.

(2) Chromatographic method.

(3) Detection method.

\section{A.1.1. Sample preparation (extraction and clean-up)}

For samples of food and food ingredients, it is likely that the analytical method which detected the unknown comprised an extraction step (usually using organic solvents) followed by some kind of purification and enrichment step to remove, for example, salts, fats and sugars (collectively known as clean-up) and concentrate the sample to improve detection limits.

Sample preparation will have a major influence on whether or not 'TTC excluded classes' can be detected. Consequently, the sample preparation technique will give information on whether or not a detected peak belongs to a particular 'TTC excluded class'. Table A1 includes examples of some common sample preparation techniques and the 'TTC excluded classes' that could be excluded. Alternatively, the table contains information on the 'TTC excluded classes' that would not be detected by a technique.

Table A1

Members of the 'TTC excluded classes' that can be excluded based on the sample preparation technique.

\begin{tabular}{|c|c|}
\hline $\begin{array}{l}\text { Sample preparation technique } \\
\text { used }\end{array}$ & ‘TTC excluded Classes' excluded ${ }^{\mathrm{a}}$ \\
\hline $\begin{array}{l}\text { Extraction (and liquid/liquid } \\
\text { partition) into non-polar } \\
\text { solvent }\end{array}$ & Aflatoxins, metals, proteins ${ }^{\mathrm{b}}$ \\
\hline $\begin{array}{l}\text { Extraction (and liquid/liquid } \\
\text { partition) into aqueous } \\
\text { solvent }\end{array}$ & Dioxins, steroids ${ }^{\mathrm{b}}$ \\
\hline Retention on ion exchange SPE & $\begin{array}{l}\text { Dioxins, aflatoxins, } \mathrm{N} \text {-nitrosamines (anion } \\
\text { exchange); depending on the SPE material }\end{array}$ \\
\hline $\begin{array}{l}\text { Steam } \\
\text { distillation/headspace } \\
\text { analysis }\end{array}$ & $\begin{array}{l}\text { Dioxins, aflatoxins, steroids, metals/non- } \\
\text { volatile compounds }\end{array}$ \\
\hline
\end{tabular}

\section{A.1.2. Chromatographic methods and exclusion of 'TTC excluded classes'}

A large number of separation techniques are available for analysing complex mixtures, such as gas chromatography for volatile substances and liquid chromatography and thin layer chromatography for non-volatile substances. For the purposes of this document gas chromatography and high performance liquid chromatography will be the only techniques considered, as they are by far the most common methods used in quality control and research \& development laboratories. Detailed information about these separation techniques and detectors is available in the literature (Snyder et al., 2010; MaMaster, 2005; Fowlis, 1995).

Detection of an unknown peak by either gas chromatography or high performance liquid chromatography can immediately allow the exclusion of certain 'TTC excluded classes'. Table A2 summarises the behaviour of the 'TTC excluded classes' by each technique. For both proteins and polymers, their presence is not as a single entity but as a collection of molecules with a wide molecular weight distribution. This presents itself as an obvious chromatographic pattern rather than a single peak.

\section{A.1.3. Detection techniques}

There are a range of detectors for both gas chromatography and high performance liquid chromatography. Typically, detector response is calibrated using standards containing known concentrations of the target analyte. However, this is not possible for an unidentified peak. In terms of the quantification of unknowns, it is important to choose a detector that gives broadly the same response to all analytes. In GC analysis, there are a range of detectors with specific response to the presence of certain chemical groups but only two approach universality: flame ionisation detection (FID) and mass spectrometry (MS). Universal HPLC detectors include refractive index, evaporative light scattering, charged aerosol discharge (CAD) and nano quantity analyte (NQAD) detectors, all of which are likely to detect most substances, although only CAD and NQAD can be considered suitable for quantification of unknowns as they have a similar response for many analytes.

A.1.3.1.. Exclusion of the GC detectable 'TTC excluded classes' by detector type. The 'TTC excluded classes' that may be analysed by gas chromatography are dioxins, organometallic molecules, steroids, $N$-nitrosamines and azoxy compounds. Table A3 summarises whether they would be detected on typical GC detections systems.

Note that a member of the COC and other 'TTC excluded classes' (particularly azoxys and steroids) may also contain another functional group that makes it detectable with other detectors. For example, a compound containing both an azoxy group and a chlorine atom will be detectable by ECD whereas it is not detectable with ECD when the chlorine is absent.

A.1.3.2.. Exclusion of the HPLC detectable 'TTC excluded classes' by detector type. With the exception of metals, HPLC methods generally cannot be used to completely exclude any 'TTC excluded

Table A2

Summary of the behaviour of the 'TTC excluded classes' upon analysis with GC and LC.

\begin{tabular}{|c|c|}
\hline Type of chromatography & $\begin{array}{l}\text { Compound classes that would not be detectable } \\
\text { with the type of chromatography due to their } \\
\text { physico-chemical properties }\end{array}$ \\
\hline Gas chromatography & $\begin{array}{l}\text { Dioxins if headspace GC } \\
\text { Steroids if headspace GC } \\
\text { Metals (except few organometallics) } \\
\text { Aflatoxin-like compounds (except at high } \\
\text { column temperatures) }\end{array}$ \\
\hline Liquid chromatography & Metals (except few organometallics) \\
\hline
\end{tabular}


Table A3

Elimination of GC detectable 'TTC excluded classes' by detector type.

\begin{tabular}{lll}
\hline $\begin{array}{l}\text { GC detector } \\
\text { responding } \\
\text { to the unknown peak }\end{array}$ & $\begin{array}{l}\text { 'TTC excluded classes' } \\
\text { detectable }\end{array}$ & $\begin{array}{l}\text { 'TTC excluded } \\
\text { classes' not } \\
\text { detectable }\end{array}$ \\
\hline MS & $\begin{array}{l}\text { Dioxins, steroids, } \\
N \text {-nitrosamines, azoxys, } \\
\text { organometallic molecules }\end{array}$ & \\
& $\begin{array}{l}\text { Dioxins, steroids, } \\
N \text {-nitrosamines, azoxys, } \\
\text { organometallic molecules }\end{array}$ & \\
FID & $\begin{array}{l}\text { Organometallic } \\
\text { molecules }\end{array}$ & $\begin{array}{l}\text { Dioxins, } N- \\
\text { nitrosamines, } \\
\text { steroids, azoxys }\end{array}$ \\
FPD & Nitrosamines, azoxys & $\begin{array}{l}\text { Dioxins, steroids } \\
\text { NPD }\end{array}$ \\
ECD & Dioxins & $\begin{array}{l}\text { Steroids, } \\
\text { nitrosamines, azoxys }\end{array}$ \\
TEA & Nitrosamines & Dioxins, steroids, azoxys \\
\hline
\end{tabular}

classes' from consideration of an unknown peak. Table A4 presents different LC detectors that have been considered and their response to 'TTC excluded classes'.

Both proteins and polymers would be easily recognisable to the analyst and will not be considered in this section. It is unlikely that dioxins would be present at a high enough level to be quantified by any technique other than GC-MS or GC-ECD but in some cases (for example contamination of guar gum with highly chlorinated dioxins from pentachlorophenol use) it would not be possible to completely exclude dioxins when HPLC is used.

A.1.3.3.. Partial identification of an unknown peak. Complete/thorough identification of a peak would theoretically require a combination of several techniques depending on the physico-chemical properties of the analyte. For a standard organic compound this could be, for example, GC-MS, ${ }^{1} \mathrm{H}-\mathrm{NMR}$ and UV or GC-MS and comparison in the GC with a standard. Such analytical examinations mostly require the analyte to be available as an isolated compound

\section{Table A4}

Elimination of 'TTC excluded classes' by HPLC detector type.

\begin{tabular}{|c|c|c|}
\hline Detector & $\begin{array}{l}\text { 'TTC excluded } \\
\text { class' }\end{array}$ & Detection of 'TTC excluded class' \\
\hline $\mathrm{DAD} / \mathrm{UV}$ & $\begin{array}{l}\text { Dioxins } \\
\text { Aflatoxins } \\
\text { Steroids } \\
\mathrm{N} \text {-nitrosamines } \\
\text { Azoxys }\end{array}$ & $\begin{array}{l}\text { Detectable only if present at } \\
\text { sufficiently high concentrations } \\
\text { Possible } \\
\text { Possible, commonly detected at } \\
240 \mathrm{~nm} \\
\text { Unlikely }^{*} \\
\text { Depends on overall structure }\end{array}$ \\
\hline Fluorescence & $\begin{array}{l}\text { Dioxins } \\
\text { Aflatoxins } \\
\text { Steroids } \\
N \text {-nitrosamines } \\
\text { Azoxys }\end{array}$ & $\begin{array}{l}\text { Excluded } \\
\text { Possible } \\
\text { Certain steroids (e.g. estradiol) } \\
\text { Unlikely* }^{*} \\
\text { Dependant on overall structure }\end{array}$ \\
\hline Mass Spectrometry & $\begin{array}{l}\text { Dioxins } \\
\text { Aflatoxins } \\
\text { Steroids } \\
N \text {-nitrosamines } \\
\text { Azoxys }\end{array}$ & $\begin{array}{l}\text { Unlikely } \\
\text { Possible } \\
\text { Possible } \\
\text { Possible } \\
\text { Possible }\end{array}$ \\
\hline $\begin{array}{l}\text { Refractive index/ } \\
\text { evaporative light } \\
\text { scattering }\end{array}$ & \multicolumn{2}{|c|}{$\begin{array}{l}\text { All 'TTC excluded classes' potentially detectable } \\
\text { although sensitivity unlikely to be sufficient for food } \\
\text { applications }\end{array}$} \\
\hline $\begin{array}{l}\text { Charged aerosol/ } \\
\text { NQAD }\end{array}$ & \multicolumn{2}{|c|}{$\begin{array}{l}\text { All 'TTC excluded classes' potentially detectable at } \\
\text { concentrations likely to be relevant to food }\end{array}$} \\
\hline
\end{tabular}

${ }^{*}$ Detection unlikely but depends of entire structure of analyte. in relatively high concentration - a condition which will not be fulfilled in many cases of food trace analysis.

Accurate mass-mass spectrometry, whether by time of flight (ToF), magnetic sector, Fourier transform or Orbitrap ${ }^{\mathrm{TM}}$, allows a definitive molecular formula (i.e. the number and type of atoms, but not the structure) to be assigned to unknown peaks. Further structural information can also be obtained from the presence of fragment ions, again with precise molecular formulae assigned.

The use of mass spectrometry can lead to partial structural identification of an unknown to varying degrees when no standard compound is available. This can influence the risk assessment as follows:

(1) Exact library match or unambiguous structure assigned from molecular formula information. Risk assessment can then take place using available toxicological information or the TTC if sufficient toxicological information does not exist. When using the TTC, structural alerts for genotoxicity can be assessed from the derived structure.

(2) An exact structure cannot be determined but a limited number of possible structural isomers can be assigned. Risk assessment can be based on the most toxic of these isomers if toxicological data are available for all or proceed via the TTC approach. All isomers would need to be checked for genotoxicity structural alerts.

(3) Only a partial structure can be assigned. The mass spectrum should be carefully evaluated to see what information can be deduced. Certain chemical groups give rise to characteristic mass losses which can help build up an idea of the structure of the molecule.

Scenario 3 above gives the greatest uncertainty since the molecular formula may not be known and all conclusions are based on interpretation. However, where characteristic functional groups can be identified and a partial picture of the structure of the molecule can be built up there is potential, at the very least, to screen for structural alerts for genotoxicity. For example, an indication of the presence of a nitro group would be the loss of both 30 (-NO) and $46\left(-\mathrm{NO}_{2}\right)$ mass units.

An example of a peak for which the structure could only be partially elucidated occurred in a food which was thermally aged to study the stability of the food. An extract of the food was analysed by GC-MS. Fig. A1 presents the gas chromatogram of the aged (top chromatogram) and of the fresh (lower chromatogram) food product. A number of peaks were detected in the aged product, which were not present in the fresh product. A standard NIST database search linked these peaks to aliphatic acids, possible breakdown products of triglycerides upon aging. However, three peaks were detected (retention time 26.6, 26.9 and $28.6 \mathrm{~min}$ ) that were identified by the NIST mass spectra database as hexadecanoic acid. Based on the mass spectrum it was likely that the substances were aliphatic acids. However, it was not possible that each had the same identity. The three peaks were therefore assumed to be aliphatic acids with varying length of the aliphatic chain. Though it was not of interest for this case to know exactly which aliphatic acids were present in the food, analysis of a mixture of known aliphatic acids would confirm their identity.

\section{A.2. STEP 3: Excluding the 'TTC excluded classes' with specific screening methods and targeted analysis}

When the approaches outlined in steps 1 and 2 do not rule out the presence of a 'TTC excluded class', targeted analysis for the 'TTC excluded classes' becomes necessary. What is described below is laborious. Depending on the number of screening methods needed, one may consider whether identification of the unknown peak 

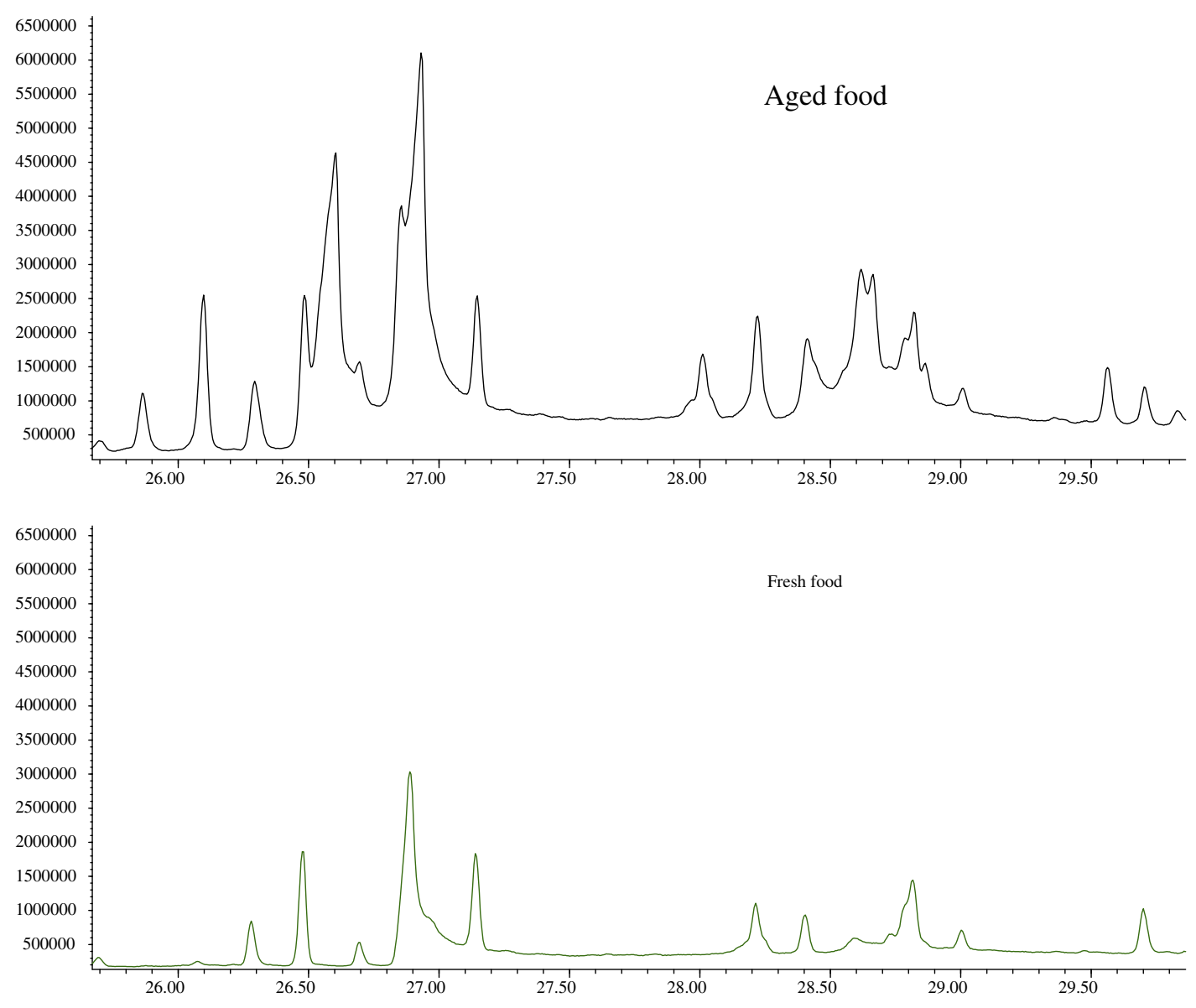

Fig. A1. GC-MS chromatogram of aged (top chromatogram) and fresh (lower chromatogram) food product.

would be a more efficient alternative. In the following subchapters the specific analytical approaches analyse for the 'TTC excluded classes' will be reviewed.

\section{A.2.1. Aflatoxins}

Aflatoxins can be isolated by immunoaffinity column (SPE) and identified by HPLC-fluorescence after post-column derivatisation (bromination), with limits of detection as low as $0.5 \mu \mathrm{g} / \mathrm{kg}$ ). This is the accepted standard approach for food analysis (ISO 16050, 2003; EN14123, 2007; EN12955, 1999; AOAC, 2008; Lerda, 2009). Alternatively, HPLC-MS/MS methods using stable isotope dilution analysis (Sulyok et al., 2007; Boonzaaijer et al., 2008) or rapid screening immunoassays (ELISA) are available for these compounds.

\section{A.2.2. N-nitroso compounds}

Levels of total $N$-nitroso substances in a sample can be screened by monitoring the liberation of NO after suitable treatment (Pignatelli and Walters, 1996). $\mathrm{N}$-nitrosamines are routinely analysed by both LC (ISO 10130, 2009; ISO 15819, 2008) and GC methods (Raoul et al., 1997), often using a Thermal Energy Analyser (TEA) detector (Fine et al., 1975). The principle of the TEA detector is the liberation of nitrogen oxide as a pyrolysis product but this may not be appropriate for $\mathrm{N}$-nitrosamides which do not yield nitrogen oxide as their main pyrolysis product (Hansen et al., 1979). Sensitive and selective methods for the determination of $\mathrm{N}$-nitrosamides are often based on measurement of their alkylation potential (Mende et al., 1989). $\mathrm{N}$-Nitrosamides are treated with alkali to give diazoalkanes which are then reacted with a suitable scavenger, typically a species containing a nitrosamine group to permit selective detection by GC-TEA.

\section{A.2.3. Azoxy compounds}

As discussed elsewhere in this paper, azoxy compounds find their origin mainly in dedicated complex chemical synthesis and it is very unlikely that azoxy substances are formed during food production/processing. Therefore it is unlikely that targeted analysis of azoxy compounds would be necessary. Due to the differing properties of substances containing azoxy groups there is no generic method for their determination and identification as an azoxy compound would require laborious comparison to relevant standards. Volatile azoxy compounds can be analysed by gas chromatography and detected by a nitrogen/phosphor detector (NPD). Most of the azoxy compounds will be non-volatile and detectable by HPLC-MS methods using appropriate analytical standards for quantification.

In general, azoxy compounds can be reduced to hydrazo compounds. Consequently any azoxy compound will disappear in the chromatogram after reduction (Wanga et al., 1999).

\section{A.2.4. Steroids}

The physical/chemical properties of steroids make them very difficult to exclude analytically as a class of compounds and it would be expected that analytical methodology would need to be developed for each specific steroid or closely related group of steroids. Typically, MS is the preferred detection technique but UV detection is quite common too, typically at a wavelength of around $240 \mathrm{~nm}$. Fluorescence detection has also been used (e.g. for estradiol). GC is frequently used for the analysis of steroids after 
derivatisation. Some steroids such as cholesterol do not contain $\mathrm{OH}$ functional groups making it possible to analyse these steroids directly by GC (Alonso et al., 1995).

It might also be possible to screen for specific steroid classes (i.e. those that act on the same receptor) by using reporter gene assays, analogous to those in use for detecting dioxins, such as the DR-CALUX system. Indeed, such systems are already commercially available for estrogens, ER-CALUX and androgens, AR-CALUX (Sonneveld et al., 2005). A number of cell based systems have been developed, often in research laboratories, with similar of even greater sensitivity than the CALUX assays. However, many are not as readily available. Whilst these reporter cell assays are very sensitive, and their use in analysing food samples is envisaged (e.g. Scippo et al., 2004b), few studies could be identified where they have been used for that purpose.

\section{A.2.5. Polyhalogenated dioxins/dibenzo furans and dioxin like polyhalogenated biphenyls}

In standard food analysis to meet regulatory requirements, there is a need to detect dioxins in food at sub part per trillion levels so analytical methodology typically involves solvent extraction (e.g. soxhlet, accelerated solvent extraction) followed by multistage clean-up (e.g. adsorption chromatography with modified silica, florisil, alumina and activated carbon). Measurement of dioxins is usually carried out by gas chromatography coupled to a high resolution mass spectrometer (Smith et al., 1984) to achieve the required sensitivity. Detection is also possible using electron capture detection (ECD) and even LC (Padrón Sanz et al., 2002) in cases where higher quantities are present.

The presence of dioxins can be screened for using the dioxin responsive chemical-activated luciferase gene expression (DRCALUX) bioassay (Scippo et al., 2004a). Extraction is as previously described but further processing is reduced to a single stage silica clean-up.

\section{A.2.6. Proteins}

Usually proteins are determined by methods such sodium dodecyl sulfate-polyacrylamide gel electrophoresis (SDS-PAGE). Here the proteins are denatured and separated in an electrical field by molecular size. Consequently information about the molecular size but not on tertiary structure and functionality is obtained.

Typically, HPLC analysis of undigested protein will give a characteristic chromatogram with separate, but often unresolved, peaks for each chain length. Where LC-MS is used, multiple charge states would be detected. It is important to note that analysis of proteins normally requires LC-MS conditions different from those used for small molecules. Therefore, it is very unlikely that an 'unknown peak' detected by LC-MS would be a protein if the instrumentation were not tuned for the analysis of proteins in the first place.

\section{A.2.7. Non-essential metals}

Following acid digestion, atomic absorption spectroscopy and particularly high resolution ICP-MS can be used to detect/quantify non-essential metals in samples (Ammann, 2007). This approach does not distinguish between inorganic or organometallic sources of the metal. Both gas chromatography (GC) (Diez and Bayona, 2008) and liquid chromatography (LC) (Gonzalez-Toledo et al., 2003) methods exist to detect specific organometallic substances that are known to occur in foods.

\section{A.2.8. High molecular weight substances such as polymers}

Polymers are separated from lower molecular weight species by size exclusion chromatography, either as a preparation technique or as the analytical separation. They can be detected by HPLC using MS, light scattering or refractive index detection in the main, although certain polymers may have properties which allow detection by UV or fluorescence detectors. Like proteins, polymers typically exist as a range of different chain lengths and are likely to give a characteristic chromatogram consisting of a separate peak for each chain length present. Mass spectrometry can confirm the mass range of the polymers detected.

\section{A.3. STEP 5: Quantification of unknowns}

Once an unidentified peak has been shown not to be part of a 'TTC excluded class', it must be quantified in order for the TTC to be applied. The following provides some guidance on analytical approaches to "quantifying" unknowns. The accuracy of the quantification of unknowns will be lower than that of targeted methods where standards are available to evaluate method performance. As for other toxicological risk assessment methods, the application of the TTC thresholds does not require high accuracy in the quantitation of the substance, as the applied extrapolation and assessment factors as well as exposure estimates rather represent orders of magnitude than highly accurate determinations.

\section{A.3.1. Extraction and clean-up}

When an unknown peak is detected using a method specifically designed to measure a different chemical entity it is important to consider whether the analytical method used could have resulted in losses of the unknown peak.

Theoretically it is possible that a substance contained in a sample at high concentration is only detected as a small peak, because the clean-up method was not ideal and led to losses. This possibility has to be considered when dealing with an unknown. Typically the parts of the method where losses can occur are as follows:

(1) Extraction: Is the solvent system used likely to favour particular analytes? For example, the most non-polar analytes would be extracted in hexane whereas more polar analytes are not. Other considerations would be the $\mathrm{pH}$ of any buffers used, dispersive sorbents added, etc.

(2) Liquid/liquid partition: As with extraction, care must be taken that any liquid/liquid partitions in the clean up are not significantly reducing recovery of the unknown peak. Solid Phase Extraction: If sorbents are used that favour specific interactions or where mixed mode sorbents are used with selective rinses these should be considered in terms of losses.

(3) Evaporative losses: Very volatile compounds may evaporate under normal sample handling, if at any stage of the analytical method solvents are removed by evaporation, potentially a proportion of the unknown peak can be lost too.

(4) Adsorption: Losses by sticking to surfaces such as glass may occur.

A starting point for any improved method should be the method by which the presence of the unknown peak was detected. Ideally, the analytical method used to quantify unknown peaks should be as general as possible along the following lines:

(1) Extraction solvents should be of mixed polarity, extracting the same sample with several different solvent systems if necessary. Extraction should be exhaustive so that further extraction of the sample gives no significant increase in measured concentration of the unknown peak.

(2) Clean-up should be minimal and broadly non-selective (for example gel permeation chromatography, GPC) without compromising chromatography and detection. Some information on the nature of the unknown peak may be derived 
from the chromatographic method by which it was originally detected and this would allow a targeted cleanup to be developed. Conditions should be used to maximise recovery (for example, careful consideration of the composition of SPE wash solvents).

(3) Any evaporative steps should be carried out carefully using gentle evaporation and a keeper (a compatible liquid of high boiling point) if very low volume is required. For volatile substances consideration should be given to specific methods such as headspace-GC or steam distillation in a closed system.

(4) Vessels used in the analysis should be carefully rinsed to minimise adsorptive losses. After any evaporative steps the walls of the vessel used should be rinsed carefully.

\section{A.3.2. Redevelopment of a method for chromatography}

If the original method by which the unknown peak was detected was not a chromatographic method (IR spectroscopy for example) then a non-selective approach should be taken to "find" the unknown peak by GC or HPLC prior to further refinement of the method. This will most likely involve analysis by a general method as described above with analysis of a sample where no unknown peak was detected to serve as a control.

\section{A.3.3. Detection and quantification}

Many analytical detectors show great variation in response between different substances. There are very few detectors available that would allow a compound of unknown chemistry to be quantified reliably without further consideration. As discussed earlier in this Appendix A, the choice is limited to mass spectrometry and flame ionisation detection for gas chromatography and corona CAD and NQAD detection for HPLC.

\section{A.3.4. Quantification of unknown peaks}

In typical analysis of trace contaminants, quantification relies almost entirely on response calibration of the instrument with an analytical standard of the target compound. With unknown substances this is not possible. However, if a range of substances of different physico-chemical characteristics can be shown to give a similar detector response, it would be reasonable to use a representative response of these substances to calibrate instrument response for an unknown.

The range of standards to be chosen would depend on what is known of the unknown peak. When very little is known of the chemistry of the unknown the range of standards incorporated into the method should be extensive, maybe up to 20 different substances. The substances should cover a wide range of properties such as polarity and $\mathrm{p} K_{\mathrm{a}}$ and include a range of functional groups (i.e. amines, alcohols, acids, etc.) whilst also being suitable for detection by the analytical method (e.g. avoid non-volatile substances for GC methods). This is to ensure that the method does not select against a particular chemical property.

In some cases, something will be known about the properties of the target substance, either from the method of analysis or due to similarities in properties with other known substances. When this is the case, 3-5 appropriate substances may be sufficient for calibration. The chosen standards should be proven to give good recovery through the analytical method.

Standards should be added at the very beginning of analysis to correct for losses through the method. The level at which they are added should be at or close to the concentration which for a particular foodstuff would equate to exposure at the TTC level of concern for the unknown.

Where the response of the standards added is largely equivalent (RSD $<30 \%$ ), the mean response should be used for calibration. For larger variations in response the standard giving the lowest response should be used for calibration.

\section{References}

Alonso, L., Lozada, L., Fontecha, J., Juárez, M., 1995. Determination of cholesterol in milk fat by gas chromatography with direct injection and sample saponification. Chromatographia $41(1 / 2), 23-28$.

Ammann, A.A., 2007. Inductively coupled plasma mass spectrometry (ICP MS): a versatile tool. J. Mass Spectrom. 42 (4), 419-427.

AOAC, 2008. Determination of aflatoxins B1, B2, G1, G2, ochratoxin A in ginseng, ginger by multi-toxin immunoaffinity column clean-up, liquid chromatographic quantitation-method. J. AOAC Int. 91, 511-523.

Ashby, J., Tennant, R.W., Zeiger, E., Stasiewicz, S., 1989. Classification according to chemical structure, mutagenicity to Salmonella and level of carcinogenicity of a further 42 chemicals tested for carcinogenicity by the US National toxicology program. Mutat. Res. 223, 73-103.

Barlow, S., 2005. Threshold of toxicological concern (TTC). A tool for assessing substances of unknown toxicity present at low levels in the diet. ILSI Europe Concise Monograph Series, The International Life Sciences Institute (ILSI), Europe Available at: <http://www.ilsi.org/Europe/Pages/TF_ThresholdToxi cological.aspx>.

Bontidean, I., Ahlqvist, J., Mulchandani, A., Chen, W., Bae, W., Mehra, R.K., Mortari, A., Csöregi, E., 2003. Novel synthetic phytochelatin-based capacitive biosensor for heavy metal ion detection. Biosens. Bioelectron. 18, 547-553.

Boonzaaijer, G., van Osenbruggen, W.A., Kleinnijenhuis, A.J., van Dongen, W.D., 2008. An exploratory investigation of several mycotoxins and their natural occurrence in flavour ingredients and spices, using a multi-mycotoxin LC-MS/ MS method. World Mycotoxin J. 1 (2), 167-175.

Boyd, G.V., 1997. Synthesis and reactions of hydrazo, azo and azoxy compounds. In: Patai, S. (Ed.), The Chemistry of the Hydrazo Azo and Azoxy Groups, vol. 2. John Wiley and Sons, Chichester (Chapter 10).

Cheeseman, M.A., Machuga, E.J., Bailey, A.B., 1999. A tiered approach to threshold of regulation. Food Chem. Toxicol. 37, 387-412.

Coulier, L., Koster, S., Muilwijk, B., van Stee, L., Peters, R., Zondervan-van den Beuken, E., Rijk, R., Rennen, M., Leeman, W., Houben, G., van Dongen, W.D., 2008. Non-target multi-component analytical surveillance of food contact materials. In: Pico, Y. (Ed.), Food Contaminants and Residue Analysis. Elsevier, Amsterdam (Chapter 22).

Cramer, G.M., Ford, R.A., Hall, R.A., 1978. Estimation of toxic hazard - a decision tree approach. Food Cosmet. Toxicol. 16, 255-276.

De Hoogenboom, R., Bovee, T., Traag, W., Hoogerbrugge, R., Baumann, B., Portier, L., van de Weg, G., de Vries, J., 2006. The use of the DR CALUX bioassay and indicator polychlorinated biphenyls for screening of elevated levels of dioxins and dioxin-like polychlorinated biphenyls in eel. Mol. Nutr. Food Res. 50, 945957.

De Waard, W.J., Aarts, J.M., Peijnenburg, A.C., De Kok, T.M., Van Schooten, F.J., Hoogenboom, L.A., 2008. Ah receptor agonist activity in frequently consumed food items. Food Addit. Contam. A. 25, 779-787.

Diez, S., Bayona, J.M., 2008. Determination of $\mathrm{Hg}$ and organomercury species following SPME: a review. Talanta 77 (1), 21-27.

European Commission (EC), 2007. Commission Directive 2007/19/EC of 30 March 2007. Available at: <http://eur-lex.europa.eu/LexUriServ/LexUriServ.do?uri=OJ: L:2007:091:0017:0036:EN:PDF>.

European Food Safety Agency (EFSA), 2008a. Note for guidance. Note for guidance for petitioners presenting an application for the safety assessment of a substance to be used in food contact materials prior to its authorisation. Available at: <http://www.efsa.europa.eu/en/scdocs/doc/21r.pdf>

European Food Safety Agency (EFSA), 2008b. Concise European Food Consumption Database, European Food Safety Authority. Available at: <http://www.efsa. europa.eu/en/datex/datexfooddb.htm>.

European Food Safety Agency (EFSA), 2009. Applicability of thresholds of toxicological concern in the dietary risk assessment of metabolites, degradation and reaction products of pesticides. Available at: <http://www. efsa.europa.eu/en/scdocs/doc/44e.pdf>.

European Medicines Agency (EMA), 2010. Questions and answers on the Guideline on the limits of genotoxic impurities. Available at: <http://www.ema.europa. eu/docs/en_GB/document_library/Scientific_guideline/2009/09/WC500002907. pdf $>$.

EN12955, 1999. Foodstuffs. Determination of aflatoxin $B_{1}$, and the sum of aflatoxins $B_{1}, B_{2}, G_{1}$ and $G_{2}$ in cereals, shell-fruits and derived products. High performance liquid chromatographic method with post column derivatization and immunoaffinity column clean up.

EN14123, 2007. Foodstuffs. Determination of aflatoxin B1 and the sum of aflatoxin B1, B2, G1 and G2 in hazelnuts, peanuts, pistachios, figs, and paprika powder. High performance liquid chromatographic method with post-column derivatisation and immunoaffinity column cleanup.

Felter, S., Lane, R.W., Latulippe, M.E., Llewellyn, G.C., Olin, S.S., Scimeca, J.A., Trautman, T.D., 2009. Refining the threshold of toxicological concern (TTC) for risk prioritization of trace chemicals in food. Food Chem. Toxicol. 47, 2236-2245.

Felter, S.P., Conolly, R.B., Bercu, J.P., Bolger, P.M., Boobis, A.R., Bos, P.M.J., Carthew, P., Doerrer, N.G., Goodman, J.I., Harrouk, W.A., Kirkland, D.J., Lau, S.S., Llewellyn, G.C., Preston, R.J., Schoeny, R., Schnatter, A.R., Tritscher, A., van Velsen, F., Williams, G.M., 2011. A proposed framework for assessing risk from lessthan-lifetime exposures to carcinogens. Crit. Rev. Toxicol. 
Fine, D.H., Rufeh, F., Lieb, D., Rounbehler, D.P., 1975. Description of the thermal energy analyzer (TEA) for trace determination of volatile and non-volatile $\mathrm{N}$ nitroso compounds. Anal. Chem. 47, 1188-1191.

Fowlis, I.A., 1995. Gas Chromatography, second ed. John Wiley and Sons Ltd, Hoboken, New Jersey.

Gold, L.S., Sawyer, C.B., Magaw, R., Backman, G.M., de Veciana, M., Levinson, R., Hooper, N.K., Havender, W.R., Bernstein, L., Peto, R., Pike, M., Ames, B.N., 1984. A carcinogenesis potency database of the standardized results of animal bioassays. Environ. Health Perspect. 58, 9-319.

Gonzalez-Toledo, E., Compano, R., Granados, M., Prat, M.D., 2003. Detection techniques in sepeciation analysis of organotin compounds by liquid chromatography. Trends Anal. Chem. 22 (1), 26-33.

Gutiérrez, J.C., Amaro, F., Martín-González, A., 2009. From heavy metal-binders to biosensors: ciliate metallothioneins discussed. BioEssays 31, 805-816.

Hansen, T.J., Archer, M.C., Tannenbaum, S.R., 1979. Characterization of pyrolysis conditions and interference by other compounds in the chemiluminescence detection of nitrosamines. Anal. Chem. 51, 1526-1528.

Hasegawa, K., Deushi, T., Yaegashi, O., Miyashita, Y., Sasaki, S., 1995. Artificial neural network studies in quantitative structure-activity relationships of antifungal azoxy compounds. Eur. J. Med. Chem. 30, 569-574.

Hill, R.A., Kirk, D.N., Makin, H.L.J., Murphy, G.M., 1991. Dictionary of Steroids. Chemical Data, Structures and Bibliography. Chapman and Hall, London.

Humfrey, C.D., 2007. Recent developments in the risk assessment of potentially genotoxic impurities in pharmaceutical drug substances. Toxicol. Sci. 100, 24-28.

ISO 10130, 2009. Nitrosamines: Detection and determination of $N$-nitrosodiethanolamine (NDELA) in cosmetics by HPLC, post-column photolysis and derivatization.

ISO 15819, 2008. Nitrosamines: detection and determination of $\mathrm{N}$-nitrosodiethanolamine (NDELA) in cosmetics by HPLC-MS-MS.

ISO 16050, 2003. Foodstuffs - determination of aflatoxin B1, and the total content of aflatoxins B1, B2, G1 and G2 in cereals, nuts and derived products - High performance liquid chromatography method.

Jeong, S.H., Cho, J.H., Park, J.M., Denison, M.S., 2005. Rapid bioassay for the determination of dioxins and dioxin-like PCDFs and PCBs in meat and animal feeds. J. Anal. Toxicol. 29, 156-162.

Kroes, R., Galli, C., Munro, I., Schilter, B., Tran, L.-A., Walker, R., Würtzen, G., 2000. Threshold of toxicological concern for chemical substances present in the diet: a practical tool for assessing the need for toxicity testing. Food Chem. Toxicol. 38, 255-312.

Kroes, R., Renwick, A.G., Cheeseman, M., Kleiner, J., Mangelsdorf, I., Piersma, A., Schilter, B., Schlatter, J., van Schothorst, F., Vos, J.G., Würtzen, G., 2004. Structure-based thresholds of toxicological concern (TTC): guidance for application to substances present at low levels in the diet. Food Chem. Toxicol. 42 (1), 65-83.

Kroes, R., Renwick, A.G., Feron, V., Galli, C.L., Gibney, M., Greim, H., Guy, R.H., Lhuguenot, J.C., van de Sandt, J.J., 2007. Application of the threshold of toxicological concern (TTC) to the safety of cosmetic ingredients. Food Chem. Toxicol. 45, 2533-2562.

Laqueur, G.L., Spatz, M., 1968. Toxicology of Cyasin. Cancer Res. 28, 2262.

Lerda, D., 2009. Mycotoxins Factsheet. Technical Note. European Commission Joint Research Centre (EC-JRC). Available at: <http://www.iss.it/binary/ogmm/cont/ JRC_50088_EN_CRL_mycotoxins_factsheet.pdf $>$.

MacKenzie, K., 1975. The chemistry of the hydrazo, azo, and azoxy groups. In: Patai, S. (Ed.). Wiley, New York, p. 344

MaMaster, M.C., 2005. LC/MS A Practical User's Guide. John Wiley and Sons Ltd, Hoboken, New Jersey.

Mende, P., Spiegelhalder, B., Preussmann, R., 1989. A sensitive analytical procedure for the detection of $\mathrm{N}$-nitrosamides via their alkylating activity. Food Chem. Toxicol. 27 (7), 475-478.

Moretti, A., Sabato, S., Siniscalco Gigliano, S., 1983. Taxonomic significance of methylazoxymethanol glycosides in the cycads. Phytochemistry 22, 115-117.

Morgan, R.W., Hoffmann, G.R., 1983. Cycasin and its mutagenic metabolites. Mutat. Res. 114, 19-58.

Müller, L., Mauthe, R.J., Riley, C.M., Andino, M.M., De Antonis, D., Beels, C., DeGeorge, J., De Knaep, A.G.M., Ellison, D., Fagerland, J.A., Frank, R., Fritschel, B., Galloway,
S., Harpur, E., Humfrey, C.D.N., Jacks, A.S., Jagota, N., Mackinnon, J., Mohan, G. Ness, D.K., Munro, I.C., Ford, R.A., Kennepohl, E., Sprenger, J.G., 1996. Correlation of structural class with no-observed-effect levels: a proposal for establishing a threshold of concern. Food Chem. Toxicol. 34, 829-867.

Munro, I.C., Renwick, A.G., Danielewska-Nikiel, B., 2008. The threshold of toxicological concern (TTC) in risk assessment. Toxicol. Lett. 180, 151-156.

Padrón Sanz, C., Sosa Ferrera, Z., Santana Rodríguez, J.J., 2002. Extraction and preconcentration of polychlorinated dibenzo-p-dioxins using the cloud-poin methodology: Application to their determination in water samples by highperformance liquid chromatography. Anal. Chim. Acta 470, 205-214.

Parry, R., Müller, J.V., 1984. Biosynthesis of elaiomycin 2. An unusual origin for the methoxyaminobutanol moiety. J. Am. Chem. Soc. 106, 5764-5765.

Pignatelli, B., Walters, C.L., 1996. Analytical techniques for total $\mathrm{N}$-nitroso compounds. Eur. J. Cancer Prev. 5, 51-58.

Poland, A., Knutson, J., Glover, E., 1985. Studies on the mechanism of action of halogenated aromatic hydrocarbons. Clin. Physiol. Biochem. 3, 147-154.

Preussmann, R., Stewart, B.W., 1984. N-nitrosocarcinogens. ACS Monogr. 182, 643 682.

Radhika, V., Milkevitch, M., Audigé, V., Proikas-Cezanne, T., Dhanasekaran, N., 2005. Engineered Saccharomyces cerevisiae strain BioS-1, for the detection of waterborne toxic metal contaminants. Biotechnol. Bioeng. 90, 29-35.

Raoul, S., Gremaud, E., Biaudet, H., Turesky, R.J., 1997. Rapid solid-phase extraction method for the detection of volatile nitrosamines in food. J. Agric. Food Chem. 45 (12), 4706-4713.

Rennen, M.A.J., Koster, S., Krul, C.A.M., Houben, G.F., 2011. Application of the threshold of toxicological concern (TTC) concept to the safety assessment of chemically complex food matrices. Food Chem. Toxicol. 49 (4), 933-940.

Rogers, K.R., 2006. Recent advances in biosensor techniques for environmental monitoring. Anal. Chim. Acta 568, 222-231.

Rulis, A.M., 1986. De minimis and the threshold of regulation. In: Felix, C.W. (Ed.) Food Protection Technology. Chelsea/Lewis, Michigan, pp. 29-37.

Scanlan, R.A., Issenberg, P., 1975. N-nitrosamines in foods. CR Food Sci. Nutr. 5 (4) 357-402.

Scippo, M.L., Eppe, G., De Pauw, E., Maghuin-Rogister, G., 2004a. DR-CALUX((R)) screening of food samples: evaluation of the quantitative approach to measure dioxin, furans and dioxin-like PCBs. Talanta 63, 1193-1202.

Scippo, M.L., Argiris, C., Van De Weerdt, C., Muller, M., Willemsen, P., Martial, J., Maghuin-Rogister, G., 2004b. Recombinant human estrogen, androgen and progesterone receptors for detection of potential endocrine disruptors. Anal. Bioanal. Chem. 378, 664-669.

Smith, L.M., Stalling, D.L., Johnson, J.L., 1984. Determination of part per trillion levels of PCDDs and PCDFs in environmental samples. Anal. Chem. 56, 1830-1842.

Snyder, L.R., Kirkland, J.J., Dolan, J.W., 2010. Introduction to Modern Liquid Chromatography, third ed. Wiley and Sons Ltd, Hoboken, New Jersey.

Sonneveld, E., Jansen, H.J., Riteco, J.A., Brouwer, A., van der Burg, B., 2005 Development of androgen- and estrogen-responsive bioassays, members of a panel of human cell line-based highly selective steroid-responsive bioassays. Toxicol. Sci. 83, 136-148.

Spatz, M., 1969. Toxic and carcinogenic alkylating agents from cycads. Ann. N.Y Acad. Sci. 163, 848-855.

Sulyok, S., Krska, R., Schuhmacher, R., 2007. A liquid chromatography/tandem mass spectrometric multi-mycotoxin method for the quantification of 87 analytes and its application to semi-quantitative screening of mouldy food samples. Anal. Bioanal. Chem. 389, 1505-1523.

UK National Statistics, 2001. National Diet and Nutrition Survey (NDNS)

Varriale, A., Staiano, M., Rossi, M., D'Auria, S., 2007. High-affinity binding of cadmium ions by mouse metallothionein prompting the design of a reverseddisplacement protein-based fluorescence biosensor for cadmium detection. Anal. Chem. 79, 5760-5762.

Walker, R., 1990. Nitrates, nitrites and $N$-nitrosocompounds: a review of the occurrence in food and diet and the toxicological implications. Food Addit Contam. A 7 (6), 717-768.

Wanga, X., Xua, M., Lianb, H., Pana, Y., Shia, Y., 1999. Reduction of aromatic azoazoxy- and nitrocompounds by ultrasonically activated nickel. Synthetic Commun. 29, 3031-3037. 